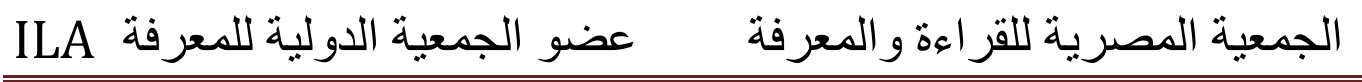

\section{الأداء الوظيفي للعاملين في المنظمات ذات الأثر الإشعاعي}

\author{
إعداد \\ أ / عادل حسن الحسينى على الريس \\ المسجل لدرجة الماجستير في الآداب قسم علم الاجتماع
}

إشراف:

د/ صبري بديع عبدالمطلب الاجناع مدرس علم الاجتماع

كلية الآداب

جامعة دمياط الاب

$$
\begin{aligned}
& \text { أ.د/ مديحة مصطفى فتحى عبد الهادى }
\end{aligned}
$$

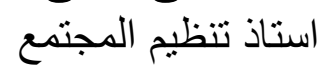

$$
\begin{aligned}
& \text { كلية الخدمة الاجتماعية } \\
& \text { جامعة حلوان }
\end{aligned}
$$




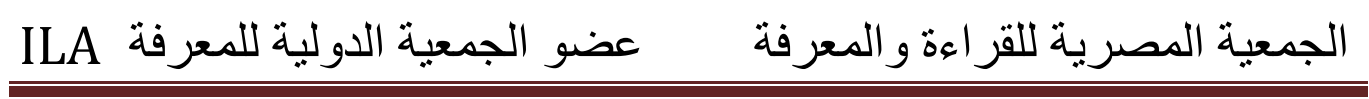




\section{مقدمة:}

يعتبر موضوع الأداء الوظيفي من المواضيع الحيويـة في حياة الأفراد والمنظمات

على حد سـواء، ذلك لأن الأداء الوظيفي لكل موظف يقاس بأسـاليب كميـة تعكس أولاً

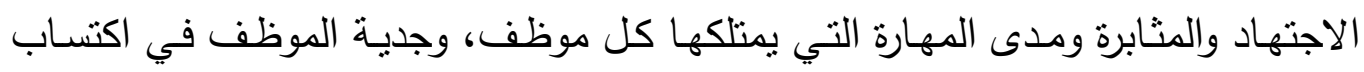
الخبرات عبر الدورات والاستفادة منها، وقد ركزت الاتجاهـات الحديثة في الإدارة على هـ

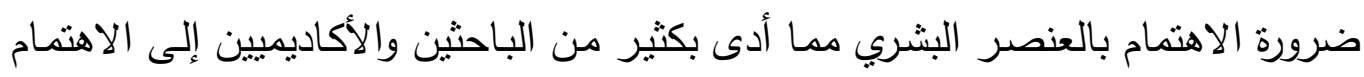

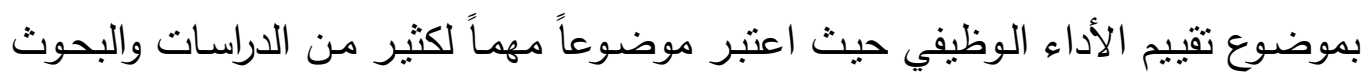
العلمية التي تتاولت الكثير من زواياه المتعددة، يضاف إلى ذلك أن أغلب الأجهزة الإدارية الحديثة بدأت تتظر إلى تقييم الأداء الوظيفي على أنه عملية حتمية وضرورية وقد يساهم في ذلك الاهتمام إصدار القوانين الحكومية الخاصـة بالعدالة في التوظيف وتكافؤ الفرص

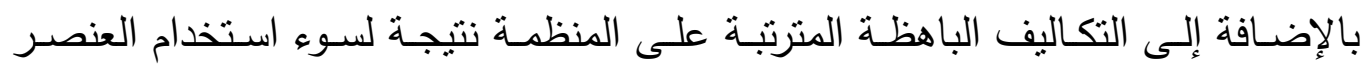
البشري بالثكل المناسب وهذا مما جعله في كثير من الأحيان مطلباً نظامياً ملزماً بقوة النظام والقانون.

يعد الأداء الوظيفي إحدى الركائز التي يستتد إليها في تحديد مسـار الموظف الوظيفي ومدى انسجامه مـع العمل وحاجته للنطوير أو قصوره في أداء واجبات وظيفته فهي أداة إصـلاح وتطوير ، ويهدف الأداء الوظيفي للموظف إلى تكريس مبدأ العدالة الذي تسعى أنظمــة الخدمـة المدنيـة إلـى تحقيقهـه حيـث إن الأداء الـوظيفي لكـل موظـف يقـاس أولاًا بالاجتهاد والمثابرة ومدي المهارة التي يملكها كل موظف، وجديـة الموظف في اكتساب الخبرات عبر الدورات والاستفادة منها، ولا بد إن يضـع في الاعتبار انه لا توجد الكفاءة المهارية عند كل موظف لكن يوجد التباين فيها، لذا ينطلق هذا البحث من اعتقاد الباحث

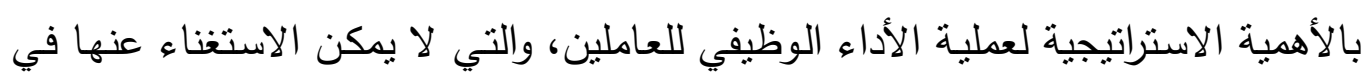
أي مؤسسة عامة كانت أم خاصة وذللك من خلال ما تقدمه في رفع كفاءة العاملين وزيادة 


\section{الجمعية المصرية للقر اعة والمعرفة عضو الجمعية الدولية للمعرفة المي}

مهاراتهم، وكذلك الميزة التنافية وتحسين النوعية والإبداع وإدارة العمليات بكفاءة وفعالية، وفعالية الإنجاز في كل الأنشطة.

وتكمـن أهميـة الأداء الـوظيفي للعـاملين في الترقيـة والنقل، وتقيـيم المشـرفين والمـديرين، وإجراء تعديلات في الرواتب والأجور ، ومقياس أو معيار ، وتقديم المشورة، ويعت تحديد الاحتياجـات التدربييـة. وذلـك كلـه بهـدف اختيـار الأفـراد الصــالحين للترقيـة، وتفــادي المحسوبية، وتتميـة المنافسـة بين الأفراد، وتتـجيع المنافسـة بين الأقسـام المختلفة لزيـادة إنتاجيتها، وإمكان قياس إنتاجية وكفاءة الأقسام المختلفة، وتسهيل تخطيط القوى العاملة. إن الأداء الوظيفي ليس هدفاً بحد ذاته وإنما هو وسيلة لبلوغ الهدف حيث ينحصر هذا الهدف في رفع كفاءة العاملين مما يفيد المنظمة في تحقيق أهدافها وإتاحة الفرصـة لهؤلاء العاملين أن يتفوقوا ويستقيدوا من فرص الترقية وزيادة الأجور وهذا يساعدهم على لهى إثباع حاجاتهم لتقدير النفس وإثبات الذات واحترام الآخرين. مما يجعل هذا الأمر ليس مجرد أسلوب من أساليب شؤون الموظفين له آنار ضعيفة أو محايدة على المنظمة وإنما للتـخل، والتأثثر على هيكل المنظمـة، وعلى اتجاهـات المـوظفين وعلى العلاقـات بـين المديرين والموظفين وبالتالي يجب علينا عدم النظر إلى الأداء الوظيفي على أنه خطوات وصفية توفر لمن يتقنها إجراء عملية تقييم الأداء الوظيفي بشكل تام وموضوعي، إلا أن الن النياء

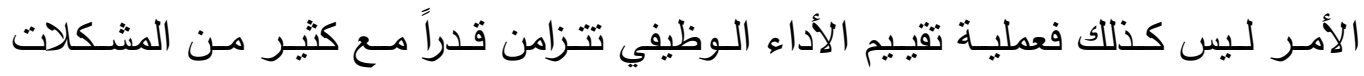
والمعوقات التي تفرض عدم تحقيق الموضوعية بشكل تام.

أولاً: مفهوم الأداء الوظيفي:

يشكل الأداء السلوك الوظيفي للموظفين في المنظمات لتحقيق أهدافها وبالتالي تبرز أهميـة تحديد ومسؤوليات الوظيفة لكي يتسنى للموظف معرفة واجباته وحقوقه ومـن ثم

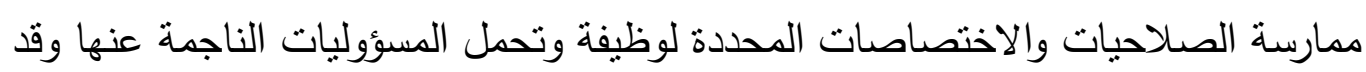
اختلف الباحثين في تعريف الأداء ورغم تشعب مفهوم الأداء وتعدد الجوانب التي يشملها 


\section{الجمعية المصرية للقر اعة والمعرفة عضو الجمعية الدولية للمعرفة المي}

هذا المفهوم إلا أنسه هناللك اتفـاق شبه عـام ببين المفكرين والكتاب حـول مفهوم الأداء الوظيفي وان وجدت بعض الفروقات البسيطة نتيجة لاختلاف المدارس الفكرية التي ينتمون إليها، وسوف يعرض الباحث مجموعة من التعاريف الخاصة بمفهوم الأداء الوظيفي: يعرف الأداء على أنه محصلة النتائج لوظيفة ما أو عمل ما أو نشاط ما.(i) وقد عرف عبد المحسن، الأداء الوظيفي على أنه المخرجات أو الأهداف التي يسعى

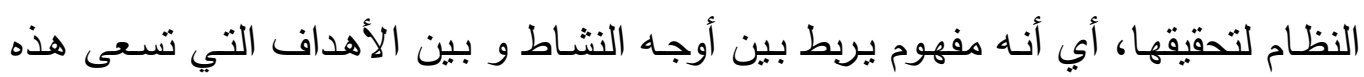
الأنشطة إلى تحقيقها داخل المنظمة. (ii) فالأداء هو استخدام الفرد لكافة قدراته وإمكاناته في تحقيق أهداف منظمته وبهذا المعنى يعتبر الأداء هو الرابطة بين الحاجات والقدرات، حيث أن القدرات الإنسانية سواء العقلية أو العضلية أو العاطفية هي الوسائل التي يعبر بها الفرد عن حاجاته، ويعمل على لى لئل إثباعها، وتلك القدرات هي حلقة الوصل بين الحاجات الأساسية للفرد وبين البيئة التي (iii). يعيش فيها يشير مفهوم الأداء الوظيفي إلى درجة تحقيق وإتمام المهام المكونة لوظيفة الفرد، وهو

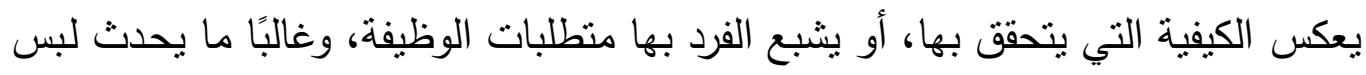

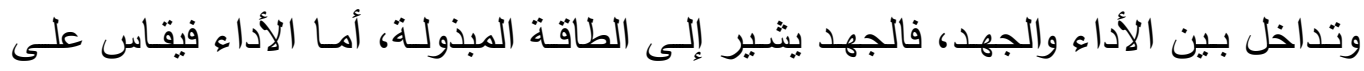
أساس النتائج التي حققها الفرد الاء ولناء

والأداء الوظيفي هو نتاج السـوك، فالسلوك هو النشـاط الذي يقوم بـه الأفراد أمسا نتاجات السلوك فهي النتائج التي تمخضت عن ذلك السلوك، مما جعل البيئة أو المصلحة النهائية مختلفة عما كانت عليه قبل ذلك السلوك. والواقع أننا نستطيع القول بأن الأداء هو التفاعل بين السلوك والإنجاز ، أو إنه مجموع السلوك والنتائج التي تحققت معا، مـع الميل بهل إلى إبراز الإنجاز أو النتائج، وذلك لصعوبة البحث بين السلوك من ناحية وبين الإنجاز والنتائج من ناحية أخرى. (v) 


\section{الجمعية المصرية للقر اءة و المعرفة عضو الجمعية الدولية للمعرفة}

كما أن الأداء الوظيفي هو جهد منسق للقيام بمهام تتضمن تحويل المدخلات إلى ذأى مخرجات ذات جودة تتفق مع مهارات العاملين وقدراتهم وخبراتهم بمساعدة العوامل الدافعة، وبيئة العمل الملائمة على القيام بهذا الجهد بدقة، وبأقصر وقت دمكن، وأقل تكلفة. وهناك من عرفه بأنه قيام الفرد بالمهام والأنشطة والواجبات المتعلقة بوظيفته المكلف بها بحكم عمله، ويمكن الحكم على أداء هذا العمل من خـلا مقاييس معياريـة خاصـة

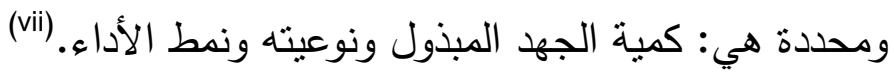

ثانياً: مكونات الأداع الوظيفي ومعاييره: 1-مكونات الأداء الوظيفي:

كثيراً ما يعبر عن الأداء ويقرن بمصطلحين هما: الكفاءة والفعالية، لأنّهما يمثلان إمّا قدرة المؤسسة على تحقيق أهدافها، وإمّا القدرة على الحصول على أكبر قدر من المخرجات من خلال المدخلات المتاحة، فالأداء يتجسد - من خلال ما سبق - بمستويات الكفاءة والفعالية التي تحققها المؤسسة، وفيما يلي توضيح أوسع لهذين العنصرين اللّذين

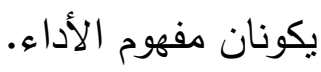

الكفاءة: تعرف الكفاءة بأنّها: "الاستخدام الأمتل للموارد المادية والبشرية المتاحة لتحقيق حجم أو مسنوى معين من النواتج أو المخرجات"(viii)،ي أنها إنجاز الأعمال بالطريقة الصحيحة"، يظهر جليّا من خلال هذه التّعاريف أنّ الكفاءة هي ترجمة للعلاقة بين المُخرجات والمُدخلات في المؤسسة. الفعالية: يركز مفهوم الفعالية على مخرجات أو نتائج أداء المؤسسـة، فالفعالية هي دالة على مدى نجاح المؤسسة في تحقيق أهدافها، واصطلاحاً هي أكثر شمولا من الكفاءة، فالفعاليـة هـي "محصـلة تفاعل مكونـات الأداء الكلي للمؤسسـة بمـا تحتويـه مـن أنشطة اهنة إدارية، ومـا يؤثز فيه من متغيرات داخلية وخارجية وهذا لتحقيق هدف أو مجموعـة من الأهداف خلال فترة زمنية معينة"(ix). 


\section{ILA الجمعية المصرية للقر اءة والمعرفة عضو الجمعية الدولية للمعرفة}

\section{r-معاييز الأداء الوظيفي:}

وهي عبـارة عن بيـان مختصـر يصف النتيجـة النهائيـة التي يتوقـع أن يصـل إليهـا الموظف الذي يؤدي عملَّ معيناً، حيث يعد معيار الأداء الدستور أو القانون الداخلي لئي

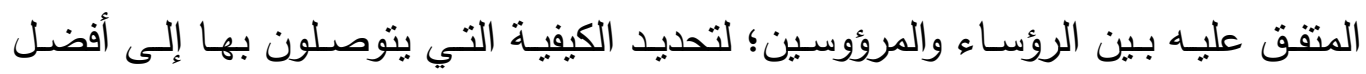

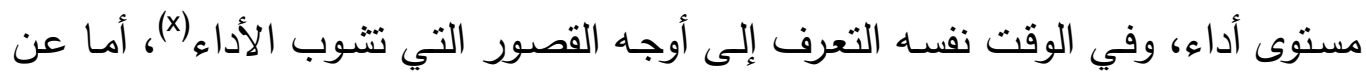
أهم معايير الأداء الوظيفي فهي كالتالي:

حسب المعيـار الـوظيفي: ينقسم الأداء حسب هذا المعيار على أسـاس الوظـائف التي تمارسها المنظمة، وهي كالآتي:

1 - أداء الوظيفـة الماليـة: يتجسـ هذا الأداء في المؤسسـات مـن خـلاص ضـمان السير الحسن والسليم والعقلاني للاعتمادات الممنوحة، كما يتجسد أداؤها في مدى شرعية وصحة

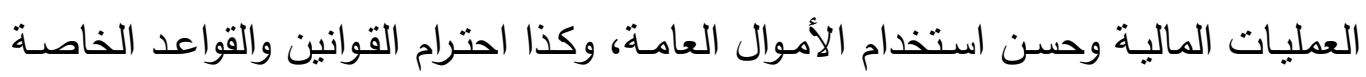
بتنفيذ الميزانية: (xi).

r - أداء وظيفة الإنتاج: نتكفل هذه الوظيفة بتلك الأنشطة التي تسمح بتحويل المدخلات (مواد أولية ولوازم العمل) إلى مخرجات (منتجات تامة الصنع، نصف مصنعة)، ويتحقق لأنق

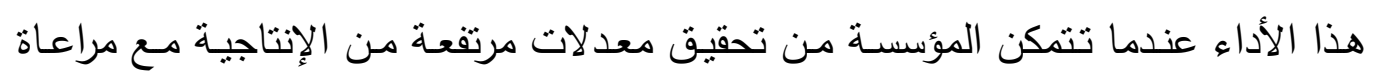
الجودة المطلوبة وفي حدود الإمكانيات المتاحة(xii). ب- وظيفة التسـويق: علما أن التسويق يتضمن تلك الأنشطة المتعلقة وضمان انسياب السلع والخدمات من أماكن الإنتاج إلى أماكن الاستهلاك، فضلا عن دراسة الأسواق ومنح الضمانات والخدمات ما بعد البيع. ع - وظيفـة التمـوين (الإمــداد): تتضــن الأنشــة المسـاعدة عـن تـوفير المـواد الخـام

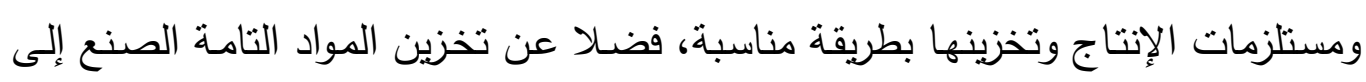
حين بيعها. 


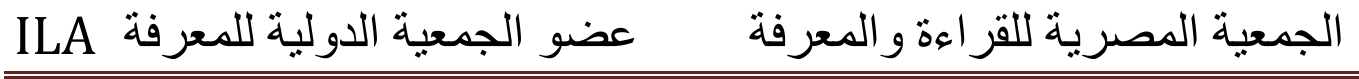

ه- وظيفة الموارد البشرية: تتمثل الأدوار الرئيسية لهذه الوظيفة في توفير اليد العاملة المؤهلة والمحفزة لتحقيق أهداف المؤسسة. (xii)

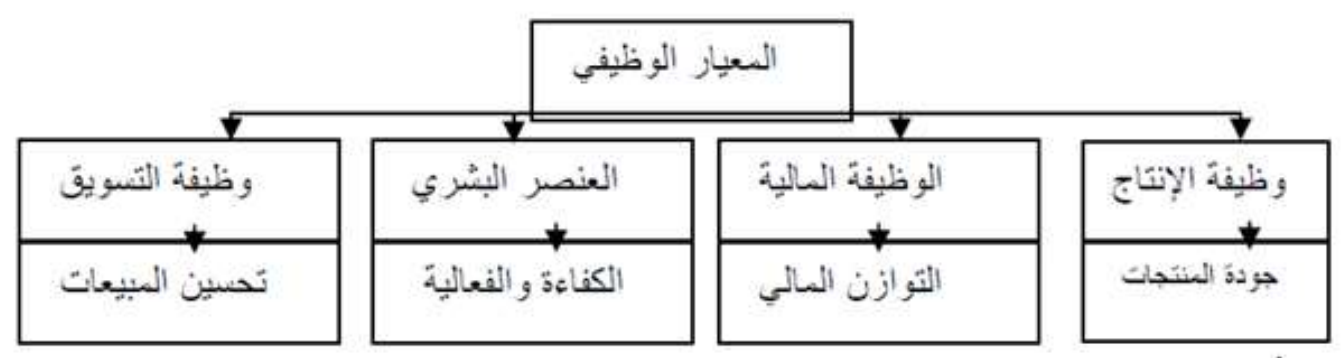

شكل رقم (ץ) مكونات المعيار الوظيفي وأهداف كل وظيفة

حسب معيار الطبيعة: ينقسم الأداء حسب هذا المعيار إلى نوعين:

ا- الأداء الاقتصــادي: يتمثنل في الاسـتخدام الأمثنل للمـوارد الماليـة والبشـرية للمنظمـة

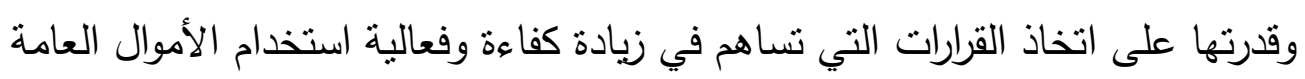

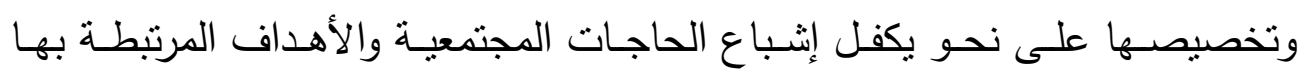
وتعزيز القدرات الإنتاجية للاقتصـاد القومي، بالإضافة إلى مدى مساهمتها في زيادة الاخل القومي في علاقته الاقتصادية مع الدول الأخرى (xiv).

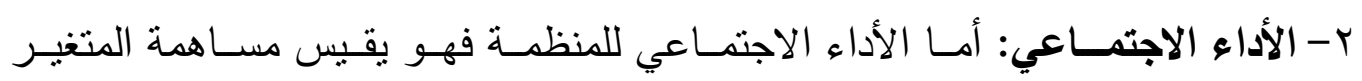

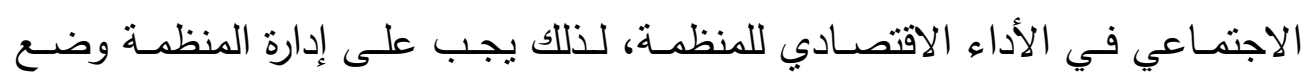

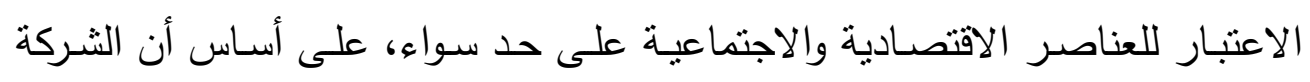

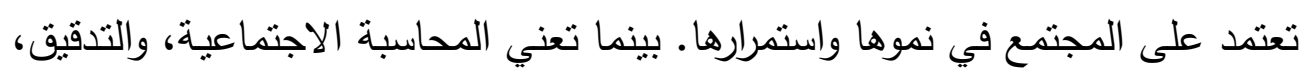

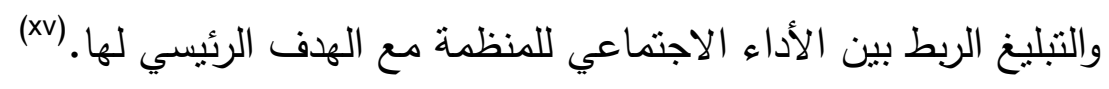

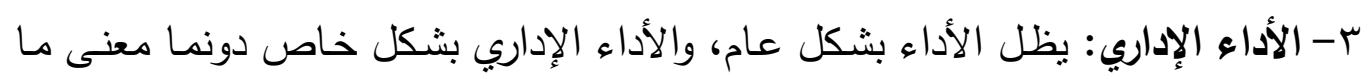

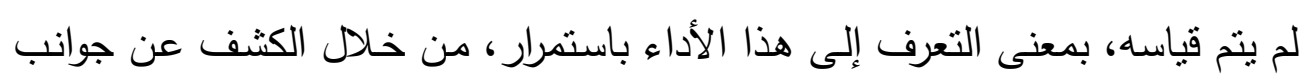

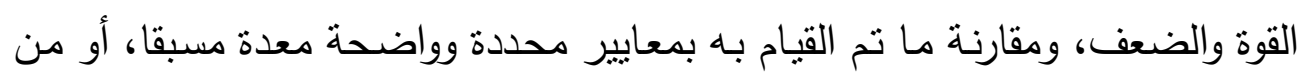




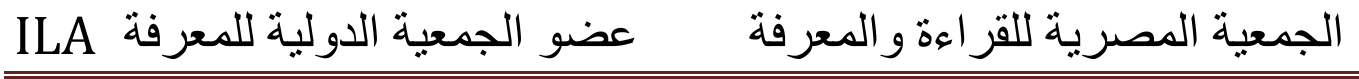

خلال مدى قيام الموظف بالمهام الموكلة اليه، تبين أن الأداء الإداري جهد بشري، يقوم به أفراد مؤهلون، وفق أنظمة وقوانين المؤسسة، بهدف تحقيق أهداف المؤسسة، والارتقاء بها باستمرار من جيد إلى الأجود، دونما الاكتفاء بمستوى معين من الأداء. هذا هو الأصل في العمل الإداري، الجميع المؤسسات ولجميع العاملين فيها. ولكن الكن

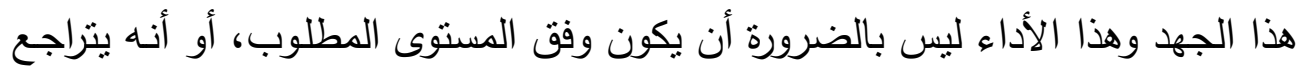

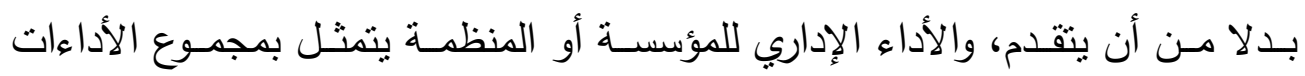

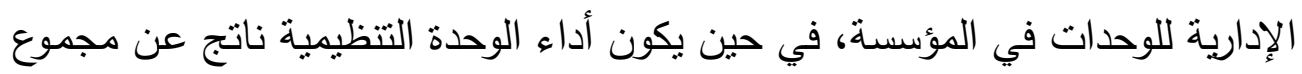

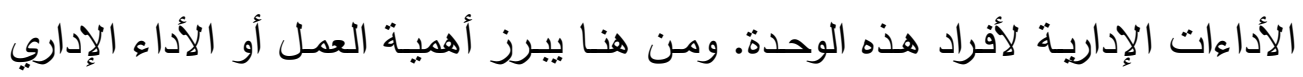

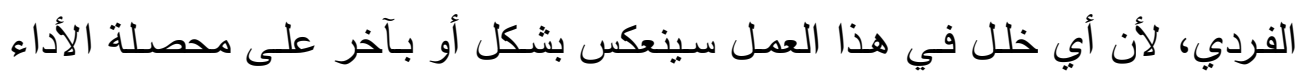

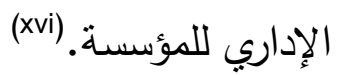
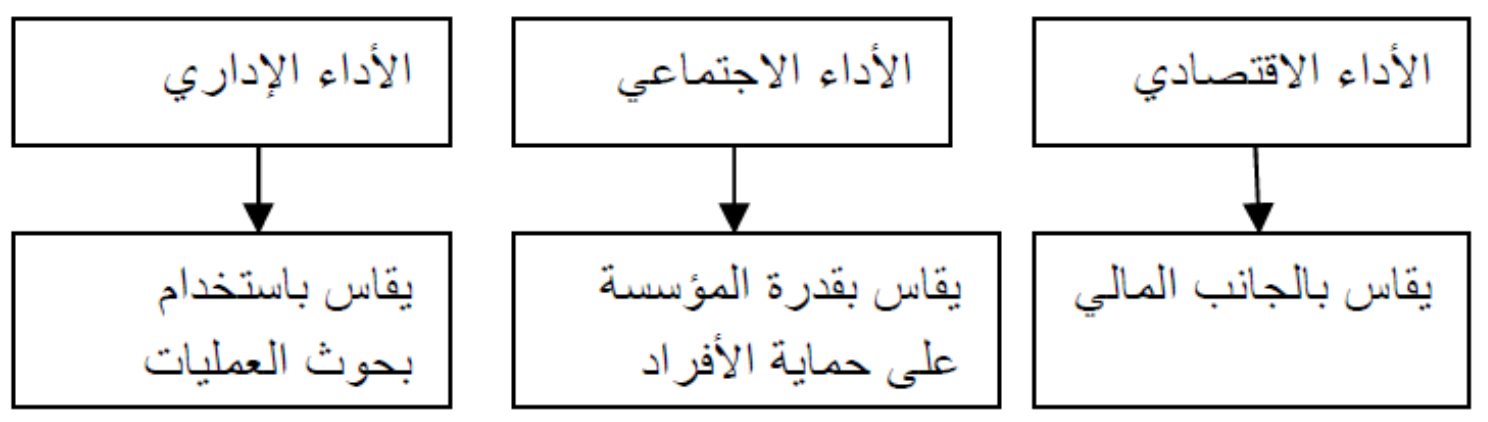

شكل رقم (r) مكونات المعيار الطبيعي للأداء وأدوات القياس المستخدمة(xvii)

حسب معيار الثمولية: ينقسم الأداء حسب هذا المعيار إلى نوعين هما:

الأداء الكلـي: هـو الذي يتجســ بالإنجـازات التـي سـاهمت جميـع العناصـر والوظـائف والأنظمة الفرعية في تحقيقها، ولا يمكن نسب الجازها إلى أب عنصر دون مساهمة باقي

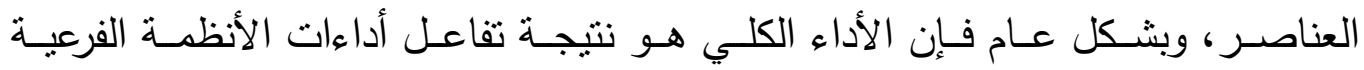




\section{الجمعية المصرية للقر اءة والمعرفة عضو الجمعية الدولية للمعرفة ILA}

1 ـ الأداء الجزئسي: هـ الذي يتحقق على مسـتوى الأنظمـة الفرعيـة للمؤسسـة فالنظـام التحتي يسـى لتحقيق الأهداف الخاصـة بـه، ومـن خـلال تحقيق النظـام الفرعي لأهدافـه

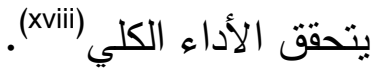

حسب معيار البيئة يتكون بالأساس من العناصر التالية:(xix)

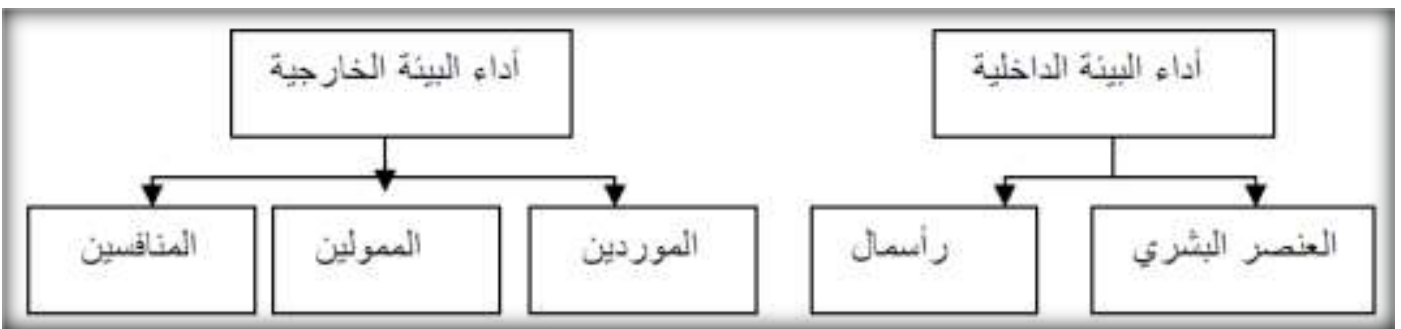

شكل رقم (؛ ) الأداء الوظيفي حسب معيار البيئة

حسب معيار الزمن يتكون بالأساس من العناصر التالية:

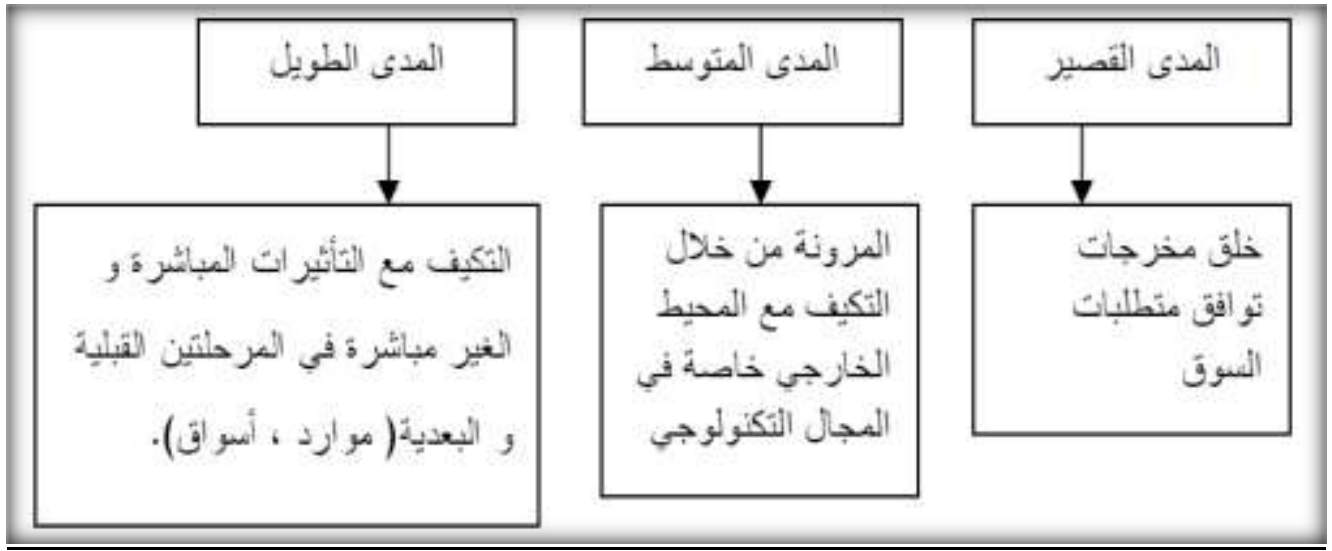

شكل رقم (0) الأداء الوظيفي حسب معيار الزمن

ثالثاً: عناصر الأداء الوظيفي:

للأداء عناصر ، فلا يمكن التحدث عن وجود أداء فعال بدونها، وذلك يعود لأهميتها في قياس وتحديد مستوى الأداء للعاملين في المؤسسات حيث تشمل الخصائص والسمات والإمكانيات والقدرات والمهارات والمؤهلات والخبرات التي يجب أن يتحلى بها العامل في 


\section{الجمعية المصرية للقر اعة والمعرفة عضو الجمعية الدولية للمعرفة المي}

عملهه وسـلوكه ليتمكن مـن أداء عمله بنجـاح وكفـاءة كـالإخلاص، المواظبـة في العملـ، التعاون، ويمكن تقسيم هذه العناصر من خلا النقاط التالية:-

\section{1 أنشطة العمل والجوانب الثابتة والمتغيرة فيها:}

إن تحديد أنشطة العمل والأهداف التي تخدمها ، وأهميتها النسبية من حيث الوقت الذي يستغرقه، والآثار المنرتبة عليها هي البداية في تحليل مكونات العمل، وتحاول الدراسات تحديد المكونات المستقرة نسبيًا في أداء العمل إضافة إلى تحديد الأنشطة والمهام التي تتغير بتغير الزمن الذي يؤدى فيه العمل، أو بتغيير الأفراد الذين يؤدون العمل، أو بتغيير الظروف أو المواقف المحيطة بالأداء، وذلك على النحو التالي:

أ- الأنشطة التي تتغير بتغير الزمن : وهي الأنشطة التي تتصف بأنها متغيرة بتغير

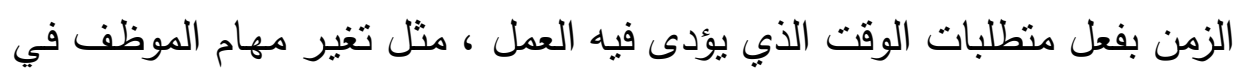

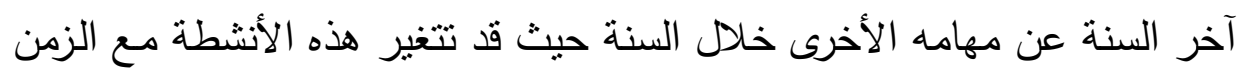
نتيجة زيادة خبرة الفرد من ممارسته للعمل. ب-الأنشطة التي تتغير بتغير أو تفاوت الأفراد الذين يؤدون العدل : وهذا يحدث

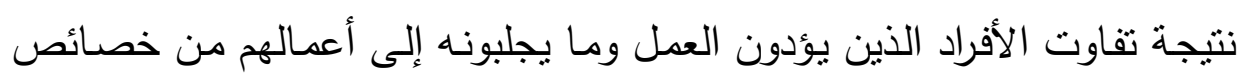
متميزة وخبرات خاصة. ج-الأنشطة التي تتغير بتغير الظروف أو المواقف المحيطة بالأداء : وهي التغيرات الناتجة من طبيعة البيئة الحركية والتي تؤدى فيها الأعمال. (xx) ץ- العلاقات بين أنثطة ومهام العمل والتصميم المناسب للعمل: إن معرفة الأنشطة يكون عن طريق تجميع هذه الأنشطة إلى مهام والمهام إلى

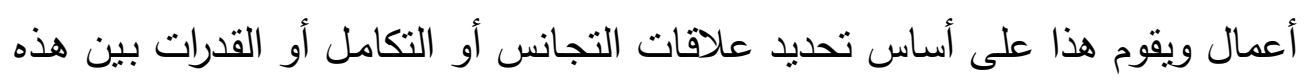
الأنشطة ليس فقط على الأنشطة والمهام التي تنتمي إلى عمل معين بل إلى العلاقات 


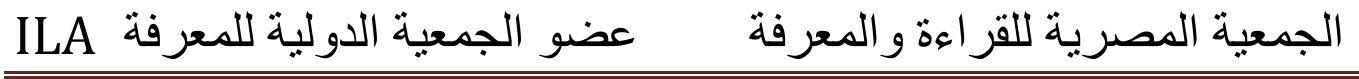

بين الأعمال المختلفة ومعرفة العلاقات الداخلية والخارجية بين الأنشطة مما قد يترتب على ذلك إعادة تصميم العمل وأحيانًا إعادة تصميم التظظيم ككل. r- المواصفات المطلوية في الفرد الأي يؤدي العمل : إن هذا العنصر يعتبر بمثابة همزة الوصل التي تربط بين بحوث تحليل الأداء

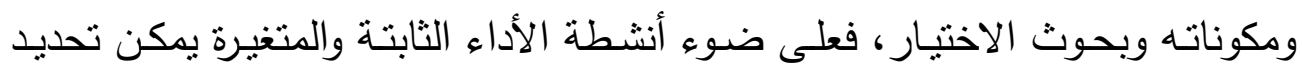
المواصفات المطلوبـة التي يجب أن تتوفر في الفرد الذي يقوم بأداء هذه الأنشطة . وهذه المواصفات تعتبر أسـاس لبحـوث الاختيـار ، والتي يجب أن تقوم على دراسـة شاملة متأنية لمختلف جوانب الأداء وربط هذه الجوانب المتعلقة بالأداء بالمواصفات

الفردية. xxi) x)

عناصر شخصية: تتعلق بشخصية العامل كالقابلية، الاستعدادات، المهارات، القيم، القدرات، الاهنمامات...الخ، والتي تسمى غالبا بالسمات الثخصية وهي صعبة القياس لأنها غير محسوسة ولا يمكن تتبعها وملاحظتها والحكم عليها بسهولة. عناصر أدائية محسوسة: تتعلق بسلوك وممارسات العامل أثناء القيام بالوظيفة وهي عناصر يمكن ملاحظتها وقياسـها كالقدرة على اتخاذ القرارات، احترام مواعيد العمل الرسمية، القدرة على حل المشكلات، التخطيط، علاقات شخصية، القيادة، المهارات

$$
\text { الإدارية، الاتصالات الثفوية...الخ. (xxii) }
$$

ويتم تحديد واختيار هذه العناصر انطلاقا من نتائج تحليل ووصف الوظائف، والتي تهنم بها ما يسمى بدراسات تحليل العمل والتي تخرج بالوصف الوظيفي الذي يحدد مهام

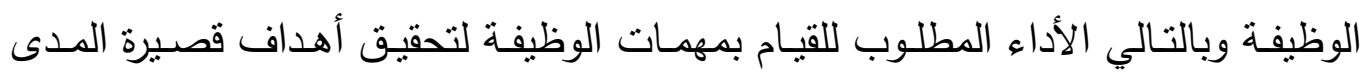
وصولا لتحقيق أهداف ذات مدى أكبر تساهم في تحقيق أهداف المؤسسة، كما ينتج عن الهن ذللك تحديد مسؤوليات كل وظيفة، مع تحديد الصفات الواجب توافرها في الثخص شاغل 


\section{الجمعية المصرية للقر اعة والمعرفة عضو الجمعية الدولية للمعرفة المي}

الوظيفة، والتي تمثل صفات وأداء العامل الكفء ذو السلوك الصحيح في العمل، ومن هذا فإن هذه العناصر تعتبر المرجعية التي يستتد إليها عند قياس كفاءة وسلوك العامل شـاغل الوظيفة وبالتالي تقييم أدائه. (xxiii)

هالمعرفـة بمتطلبـات الوظيفـة: وتشــل المعـارف العامـة، والمهارات الفنبـة، والمهنيـة

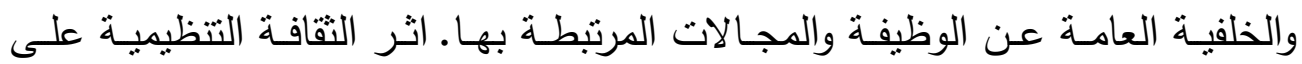
مستوى الأداء الوظيفي نوعية العمل: وتتمنل في مدى ما يدركه الفرد عن عمله الذي يقوم بـه وما بمتلكه من رغبة ومهارات وبراعة وقدرة على التتظيم وتتفيذ العمل دون الوقوع في الأخطاء. كميـة العمل المنجز: أي مقدار العمل الذي يستطيع الموظف وفئ إنجازه في الظروف العادية للعمل، ومقدار سرعة هذا الإنجاز .

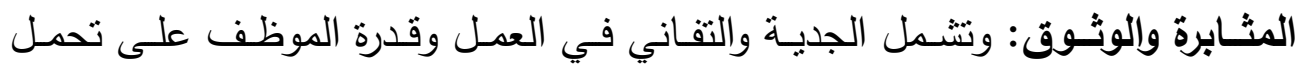
مسئولية العمل وإنجاز الأعمال في أوقاتها المحدد، ومدى حاجة هذا الموظف للإزشئاد والتوجيه من قبل المشرفين، وتقييم نتائج عمله. (xxiv) كفايات الموظف: وهي تعني ما لدى الموظف من معلومات ومهارات واتجاهات وقيم، وهي تمنل خصائصه الأساسية التي تتتج أداءً فعالاً يقوم به ذلك الموظف. ببيئة التظيم: وتتضمن العوامل الداخلية التي تؤثر في الأداء الفعَّال: التتظيم وهيكله وأهدافه وموارده ومركزه الاستراتيجي والإجراءات المستخدمة، والعوامل الخارجية مثنل العوامل الاقتصادية والاجتماعية والتكنولوجية والحضارية والسياسية والقانونية.(xxv) العناصر التنفيذيـة: كالقدرة على تحديد منطلبات إنجاز العمل وذلك من خلال تحدّد الموارد الفنية والبشرية اللازمة لإنجاز العمل، وتتجز العمل في ضوء الموارد التي تم تحديدها بفعالية. العناصر الأكاديمية: كالمعرفة بنظم العمل وإجراءاته، والمعرفة بأهداف ومهام العمل، والمعرفة بالأسس والمفاهيم الفنية المتعلقة بالعمل. 


\section{ILA الجمعية المصرية للقر اءة والمعرفة عضو الجمعية الدولية للمعرفة}

العناصــر التطويريــة: كالمتابعـة لمـا يسـتجد فـي مجـال العــل، وتقــيم الأفكـار

$$
\text { والمقترحات، وإمكانية تحمل مسؤوليات أعلى. }
$$

العناصر الأخلاقية: كالمحافظة على أوقات الدوام، والقدرة على الحوار وعرض التهله الرأي، والاهتمام بالمظهر ، وتقدير المسؤولية، وحسن التصرف.

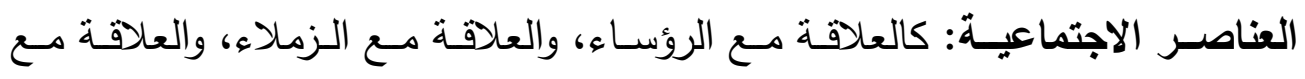

$$
\text { المراجعين. (xxvi) }
$$

\section{- وقد حدد " هاينز (Haynes) " ثلاثة عناصر للأداء وهى:-}

1 -الموظف :من حيث ما يمنلكه الموظف من معرفة ومهارات واهتمامات وقيم

$$
\text { واتجاهات ودوافع. }
$$

r -الوظيفة: من حيث ما تتصف به الوظيفة من متطلبات وتحديات وما تقدمه من فرص عمل ممتع ، فيه تحدٍ ويحتوي على عنصر التغذية الراجعة كجزء منه. r -الموقف: من حيث ما تتصف بـه البيئة التتظيمية حيث تؤدى الوظيفة والتي تتضمن مناخ العمل والإثراف ووفرة الموارد والأنظمة الإدارية والهيكل التتظيمي. (xxvii) وهنا يجب الإشـارة إلى أن الأداء ليس هدفا في حد ذاته وإنما هو وسيلة لتحقيق هدف يتمنل في النتائج والخدمات التي أنشئت المنظمة من أجلها، ولهذا بنظر إلى الأداء على أنـه" الترجمـة العملية لكافـة مراحل التخطيط في المنظمـة، وهو بذلك يحتل الدرجـة الثانيـة في الأهمية بين الوظلئف الأساسية للإدارة حيث يأتي بعد وظيفة التتظيم فمنتلا يمكن لأي منظمسة حكوميـة أو مؤسسـة عامـة أن تخطط وتنظم إلا أنها قد لا تسـنطيع

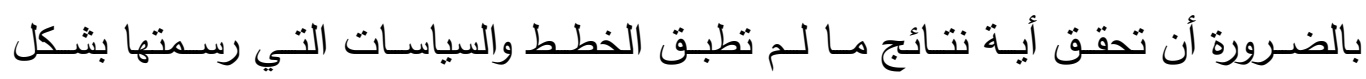
(xxviii) صحيح. 


\section{الجمعية المصرية للقر اءة والمعرفة عضو الجمعية الدولية للمعرفة}

\section{رايعاً: محددات الألداء الوظيفي:}

يُعد الأداء الوظيفي حصيلة تفاعل مجموعة من المحددات، ورأي البعض أن المقدرة والرغبة في العمل يتفاعلّن معاً لتحديد مستوى الأداء، ويتمتل ذلك من خلّل المعادلة الآتية: مستوى الأداء= القدرة على العمل × الرغبة في العمل.

\section{إلا أن هناك محدات تم الاتفاق عليها من عدد من الباحثين وهي:}

- الدافعيـة: وتعرّف بأنها: القوى الكامنـة داخل الفرد والتي تؤثر أو تحدد مستوى واتجاه

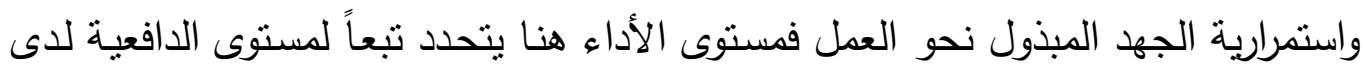
الموظف.

- قدرة الفرد على أداء العمل: وهي الخصائص الثخصية التي لا تتغير أو تثقلب خلّل فترة زمنية قصيرة، وتتألف من محصلة من المعرفة أو المهارات وتتشل التدريب والتعليم والخبرات، وهي تحدد فاعلية الجهد المبذول.

- إدراك الدور: ويعني تصور الفرد للدور، وانطباعه عن السلوك والأنشطة التي يتكون منها عمله، وعن الكيفية التي ينبغي أن يمارس بها دوره في المنظمة. فالأداء الوظيفي هو محصلة تفاعل كل من الدافعية والقدرات وادراك الفرد لدوره؛ ويتمثل في المعادلة الآتية: الأداء الوظيفي= الدافعية × القدرات× ادراك الدور . بيئة العمل: يؤثز مكان العمل في الأداء الوظيفي؛ لهذا يجب الاهتمام بـه؛ لتحقيق الراحة والرضـا للعاملين، وذلك من خلّل توفير بيئة عمل داخلية تشمل على بيئة ماديـة مناسبة؛ فضلَّ عن نمط القيادة والأنظمـة والقوانين العادلة، ويتمثل في المعادلة الآتيـة: الأداء الوظيفي= الدافعية × ادراك الدور × بيئة العمل. (xxix) 


\section{الجمعية المصرية للقر اءة والمعرفة عضو الجمعية الدولية للمعرفة}

ولتحقيق مستوى مرضي من الأداء لابد من وجود حد أدنى من الإتقان في كل مكونات الأداء، بمعنى أن الأفراد عندما يبذلون جهودا قائمة ويكون لديهم قدرات متفوقة الإنة ولكنهم لا يفهمون أدوارهم فان أدائهم لن يكون مقبولا من وجهة نظر الآخرين. فبرغم بذل جهد كبير فان هذا العمل لن يكون موجه في الطريق الصحيح، وبنفس الطريقة فان الفرد

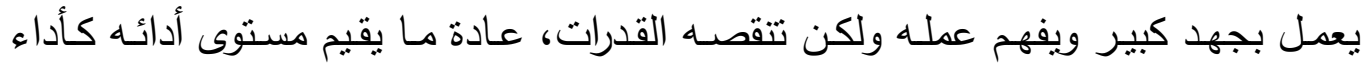
منخفض، وهناك احتمال أخير وهو أن الفرد قد يكون لديه القدرات اللازمة والفهم اللازم

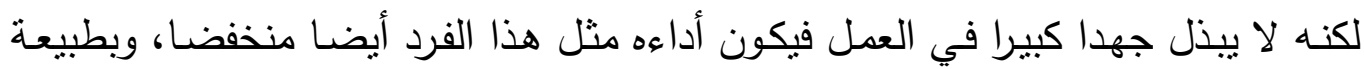

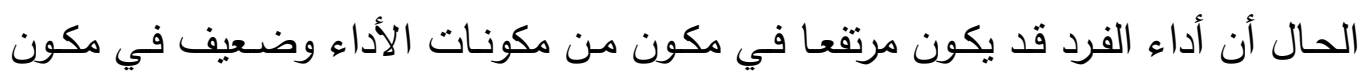

\section{خامساً: أبعاد الأداء الوظيفي:}

على الرغم من كثرة الاهتمـام بموضوع الأداء سواء على مستوى الفرد أو مستوى

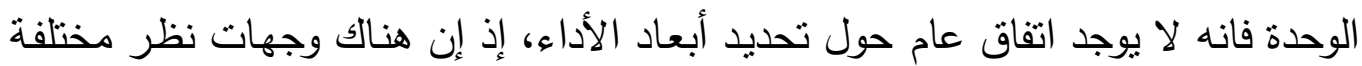

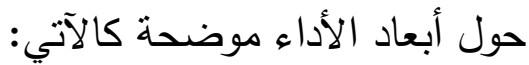
أ- كمية الجهد المبذول: تعبر عن مقدار الطاقة الجسمانية أو العقلية التي يبذلها الفرد خلال فترة زمنية، وتعتبر الدقاييس التي تقيس سرعة الأداء أو كميته في خلال فترة معينة معبرة عن البعد الكمي للطاقة المبذولة. ب - الجهد المبذول: فيعني مستوى بعض الأنواع للأعمال، قد لا يهتم كثيرا بسرعة

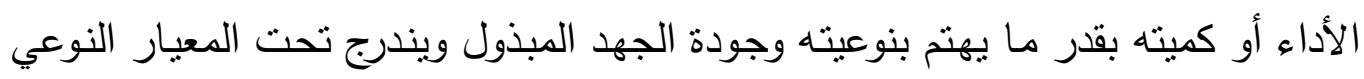
للجهد الكثبر من المقاييس التي تقيس درجة مطابقة الإنتاج للمواصفات وخلوه من الأخطاء الأبناء ودرجة الابتكار والإبداع في الأداء.

ج- نمط الأداء: يقصد به الأسلوب أو الطريقة التي تؤدي بها أنشطة العمل، فعلى أساس

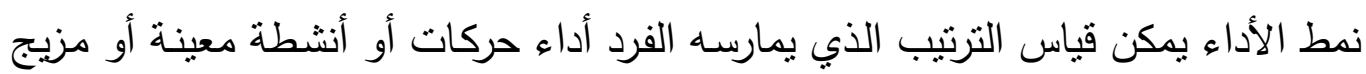




\section{الجمعية المصرية للقر اعة والمعرفة عضو الجمعية الدولية للمعرفة المي}

هذه الحركات أو الأنشطة إذا كان العمل جسمانيا بالدرجة الأولى، كما يمكن أيضـا قياس

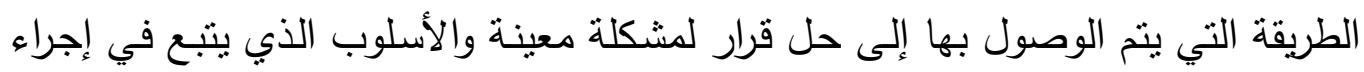
بحث أو دراسة. (xxxi)

ومنهم من يرى أن الأداء مكون من البعد التنظيمي والبعد الاجتمـاعي والبعد البيئي كما يلي:

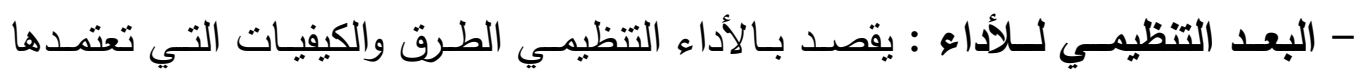
المؤسسة في المجال التتظيمي بغية تحقيق أهدافها، ومن ثم يكون لاى مسيري المؤسسة معايير يتم على أساسها قياس فعالية الإجراءات التتظيمية المعتمدة وأثرها على الأداء؛ مع لع لئه

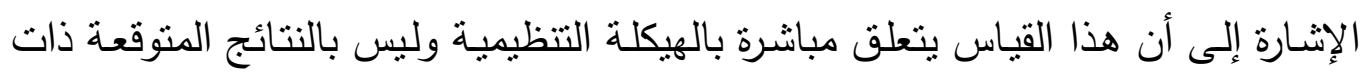

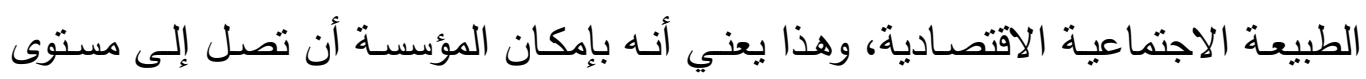
فعالية أخر ناتج عن المعايير الاجتماعية والاقتصادية يختلف عن ذالك المتعلق بالفعالية التنظيمية.

- البعد الاجتمـاعي لـلأداء: يشير البعد الاجتمـاعي للأداء إلى مدى تحقيق الرضـا عند

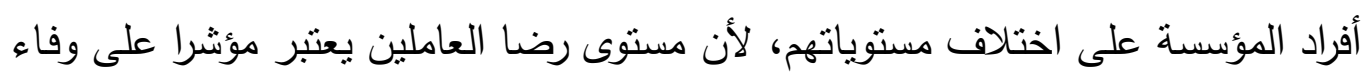

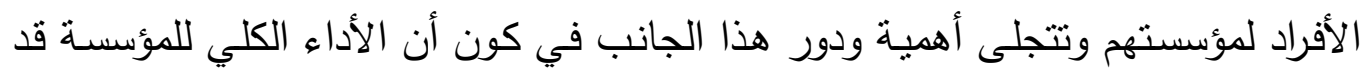

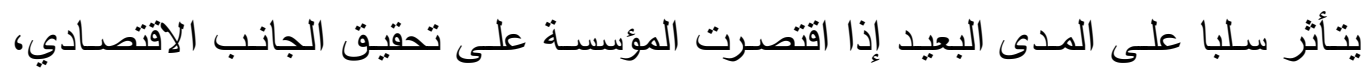

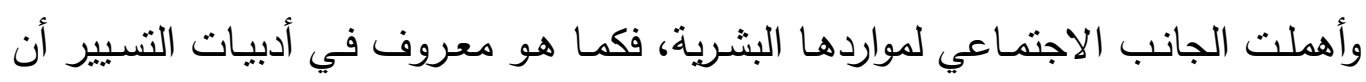
جودة التسيير في المؤسسة ترتبط بمدى تلازم الفعالية الاقتصادية مع الفعالية الاجتماعية؛

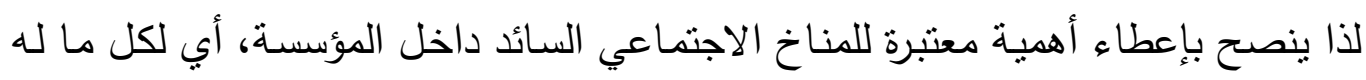

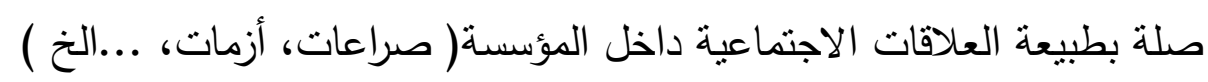

- البعد البيئي: والذي يرتكز على المساهمة الفاعلة للمؤسسة في تتمية وتطوير بيئتها. 


\section{الجمعية المصرية للقر اعة والمعرفة عضو الجمعية الدولية للمعرفة}

إذاً نستتتج مما سبق أن هذه المعايير المعتمدة في قياس الفعالية التنظيمية تلعب دوراً

هاماً في تقويم الأداء، حيث تتيح للمؤسسة إدراك الصعوبات التنظيمية في الوقت المئد الملائم

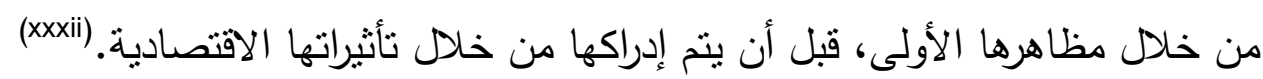

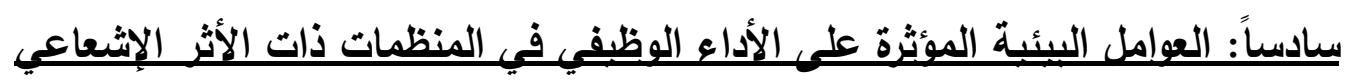

يمكن القول أن أية منظمة لا يمكن أن تعيش منعزلة عن البيئة المحيطة، فهي تعيش

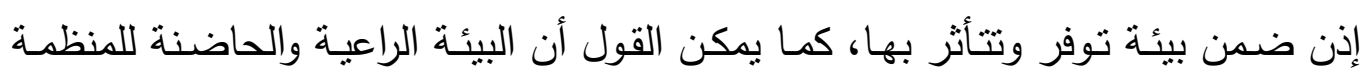

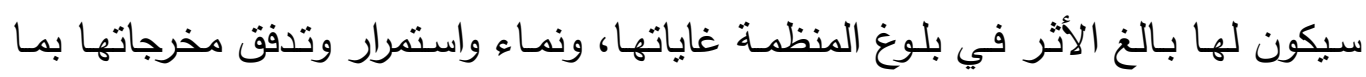

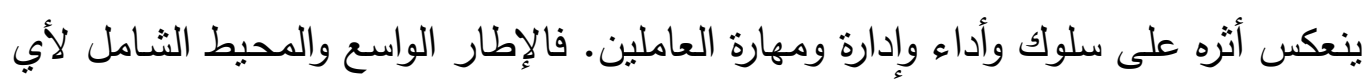

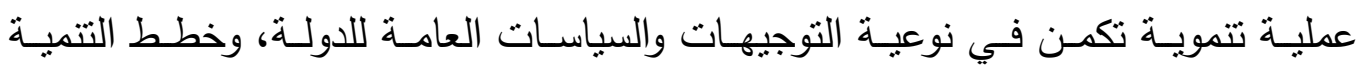

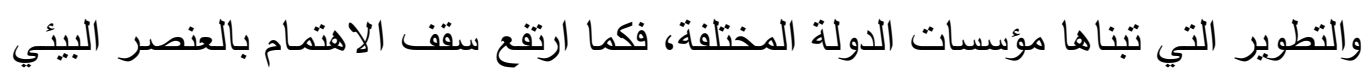

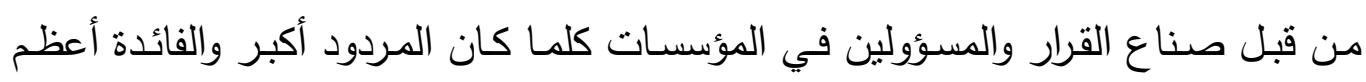
وأثنمل.

وفي ضوء ذلك، فإنه من الضـروري على المنظمـة أن تأخذ بعين الاعتبار كافة

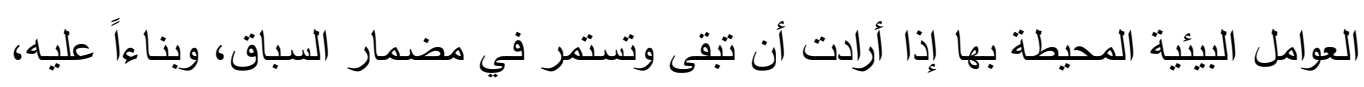

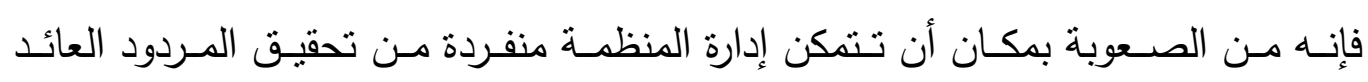

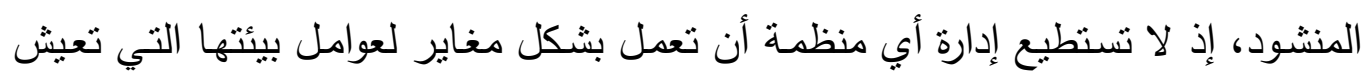

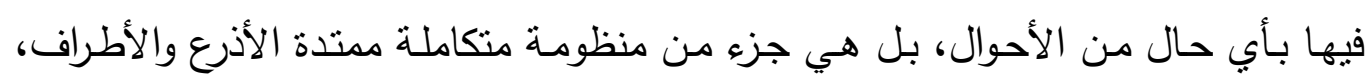

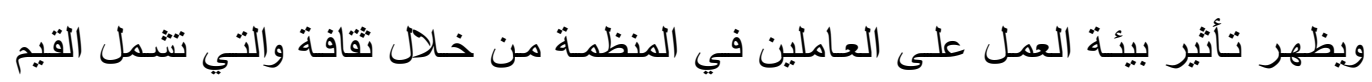

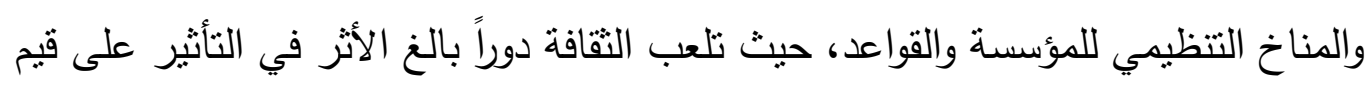

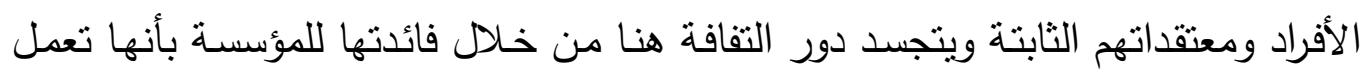
على خلق بيئة مناسبة نساعد على تطوير الأداء للعاملين، كما يمكن أن تلعب دوراً سلبياً 


\section{الجمعية المصرية للقر اعة والمعرفة عضو الجمعية الدولية للمعرفة المي}

يتمثل في أنها قد تضر المؤسسة بوضع المعوقات التي تفوق تحقيق استراتيجيات المنظمة وتنبب مقاومة التغيير وعدم الالنزام. (xxxiii)

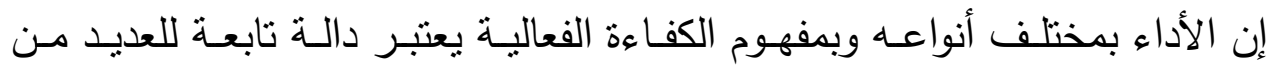

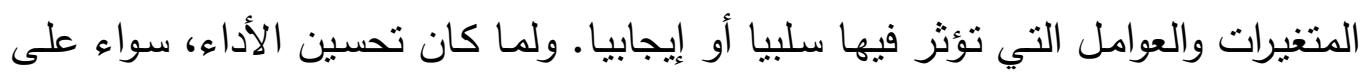
مستوى الأنظمة الفرعية أو على مستوى المؤسسة ككل، هو الهدف من وراء أغلب البحوث التي تتتاولته بشكل مباشر أو غير مباشر ، فإن الباحثين (كل حسب موضوع بحثه) سعوا

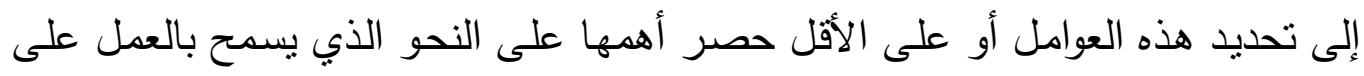

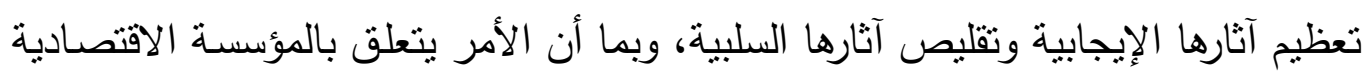
فإن العوامل الاقتصادية هي الأكثر انعكاسا على الأداء وذلك نظرا الطبيعة نشاط المؤسسة الإنه من جهة ولكون المحيط الاقتصـادي عمومـا يمثل مصسدر مختلف مواردهـا و مسـتقبل منتوجاتها من جهة أخرى. وهي بدورها تتقسم حسب شموليتها إلى عوامل اقتصادية عامـة كالفلسـفة الاقتصـادية للدولـة، معـلات نموهـا الاقتصـادي، سياسـات التجـارة الخارجية، معدلات التضخم، أسعار الفائدة.. الخ. وإذا كانت العوامل الاقتصادية تعتبر أكثر العوامل، غير الخاضعة لتحكم المؤسسة، تأثثرا على الأداء فإن العوامل الاجتماعية والثقافية لا تقل عنها أهمية ولا تأثيرا وذلك نظرا لأهمية البعد الاجتماعي في محيط المؤسسة من جهة ومساهمة عوامله في كثير الأحيان في تغيير العوامل الأخرى (الاقتصادية والسياسية...) من جهة ثنانية. وإلى جانب العوامل

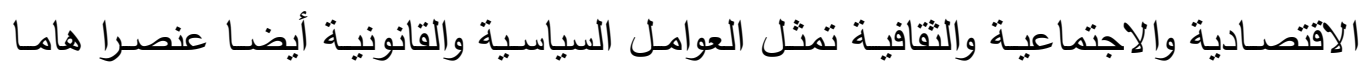
بالنسبة للمؤسسـة بفرصها ومخاطرها وانعكاسـات تغيراتها السريعة والمفاجئة على أدائها، ونذكر من بين هذه العوامل الاستقرار السياسي والأمني للاولة، السياسـة الخارجية، انتشـار الأحزاب السياسية، المنظومة القانونية، أحكام وقرارات المحاكم...الخ. وبما أن تغيرات هذه العوامل هي من إفرازات الحسابات السياسية فإن المؤسسات الاقتصادية أصبحت في كثير من الدول حتى المتقدمة منها تتذخل لتكييف تغيرات هذه العوامل وفقا لمصالحها، ولنا في 


\section{الجمعية المصرية للقر اعة والمعرفة عضو الجمعية الدولية للمعرفة المي}

قرارات الولايـات المتحدة الأمريكيـة المتعلقة بإقامـة علاقات اقتصـادية قبـل السياسية مـع الفيتنام خير مثال على ذلك. (xxxiv)

وعلى غرار العوامـل السـابقة فإن العوامـل التكنولوجيـة من بينها المعـارف العلميـة، البحث العلمي، والإبداعات التكنولوجية، تداول براءات الاختراع..الخ، تمثل هذه العوامل عنصر بالغ الأهمية ضمن متغيرات الدالة التي تربط المنظمة بعوامل محيطها ذلك لأن

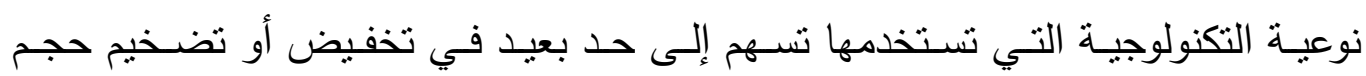
التكاليف، تحديد نوعية المنتجات، تحديد كيفية معالجة المعلومات مما بسهم في تدنية أو تعظيم مستويات الأداء، وعليه يجب على المنظمة متابعة التطورات التكنولوجية والتنبؤ بها وتقييمها، وتحديد أثنارها سواء بالنسبة للصناعة التي تنتمي إليها أو إلى الصناعات التهات الأخرى

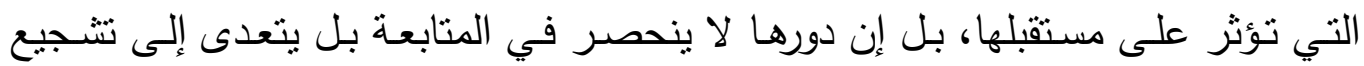
بحوث التطوير والتتمية على المستوى الداخلي لها من اجل أن تكون سباقة إلى الإبداع والاختراع وبالتالي التحسين الدائم لمختلف أنشطتها. (xxxv)

\section{- الإهيكل والمناخ التنظيمي: -}

الهيكل التظيــي هو عبـارة عن البنـاء أو الثـكل الذي يحدد التركيب الداخلي

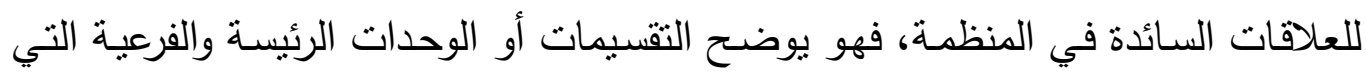
تضطلع بمختلف الأعمال والأنشطة التي بتطلبه تحقيق أهداف المنظمة. وهـو يشــل حجم المنظمـة ونمط السـلطة ونمط اتخـاذ القرارات، ذلك أن طبيعـة الهيكل التنظيمي ونظرة العاملين في التنظيم إليه تؤثز في قدرتهم على المشاركة والإبداع، وانه

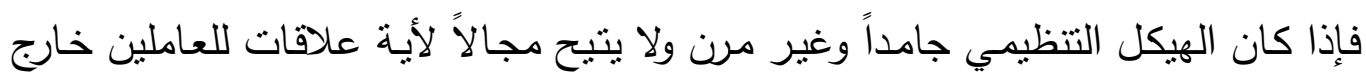
إطاره، فإن ذلك يؤدي بالعاملين إلى التخوف من أية اتصالات خارج هذا الإطار، ويجعلهم غير متحمسين لاقتراح مـا من شـأنه تحسين العمل، وعلى العكس من ذلك فإن الهيكل التتظيمي المرن والذي ينظر إليه كأسـاس عام لتحديد العلاقات التتظيميـة بمكن لـه أن 


\section{الجمعية المصرية للقر اعة والمعرفة عضو الجمعية الدولية للمعرفة ILA}

يتطور ليستوعب المتغيرات المستجدة، ويشجع العاملين على الاجتهاد لتطويره وتحسينه مما يساعد على تحقيق الأهداف.

فالهيكل التنظيمي لأي مؤسسة له تأثير كبير على تحقيق المؤسسة لأهدافها بكفاءة

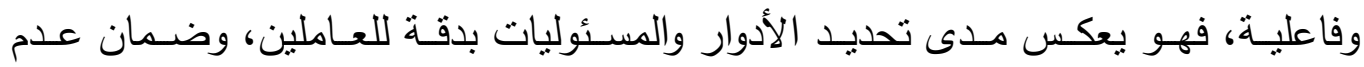
الازدواجية في المسئوليات، وكذلك طبيعة الاتصـال بين العاملين والإدارة، وبين العاملين وبعضهم البعض، وكذلك نوع العلاقات السائدة داخل المؤسسة. (xxxvi)

ويتطلب نجـاح المنظمـات في تحقيق أهدافها توافر عدد من المتغيرات التتظيميـة

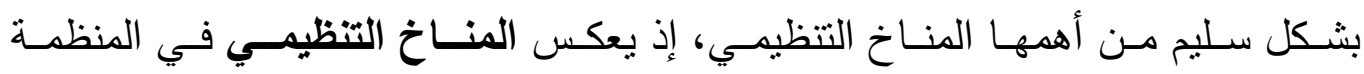
شخصيتها، ويمثل المناخ التظظيمي بيئة العمل الداخليـة بمختلف متغيراتها وخصائصـها وتفاعلاتها، حيث يلعب المناخ التنظيمي دوراً كبيراً في ترصين السلوك الأخلاقي والوظيفي

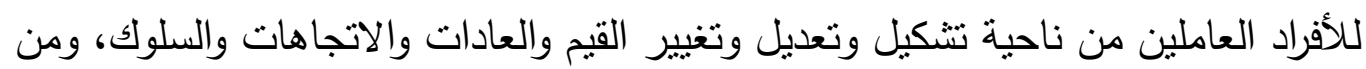
هنا يمكن القول إن المناخ التظظيمي يمثل شخصية المنظمة بكل أبعادها، وإن نجاحها في خلق المناخ الملائم للأفراد من شأنه أن يشجع على خلق أجواء عمل هادفة ترصن سبل الثبات والاستقرار للأفراد والتتظيم على حد سواء إذ إن الأفراد في البيئة التظيمية الفاعلة

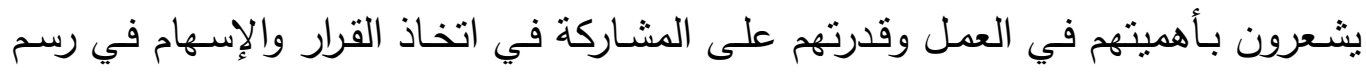
السياسات والخطط ويسود شعور بالثقة بين الإدارة والأفراد. (xxxvii)

وتزداد أهميـة وجود منـاخ تتظيمي صحي في ظل التغيرات البيئية السربعة التي تعيشها المنظمات والمنافسة الثديدة والدخول إلى العولمة والتغير التكنولوجي السريع، مما يفرض على المنظمـة الإبداع والتطوير المستمرين، إذ إن الإبداع هو العملية التي يكمن

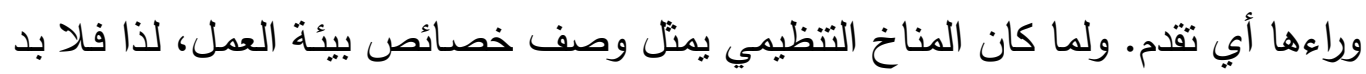
من أن يتأثز سلوك الأفراد الإبداعي بالمناخ النتظيمي السائد فإما أن يكون مشجعاً للإبداع

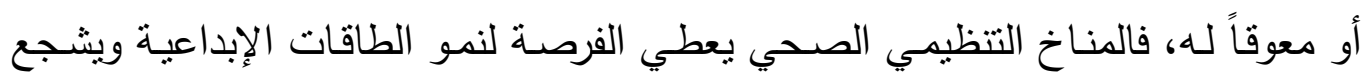




\section{الجمعية المصرية للقر اعة والمعرفة عضو الجمعية الدولية للمعرفة المي}

التجديد ويمنح الأفراد مجالاً أوسع في العمل والاتصـالات واتخاذ القرارات، ويقدم الحوافز الماديـة والمعنويـة، فالمنظمات المبدعة هي التي توفر مناخًا تتظيميًا ملائيًا يتأصل فيـه الإبداع كهدف مؤسسي متجدد، وتجعل من الإبداع مهمة أساسية وحيوية يشترك بها كافة

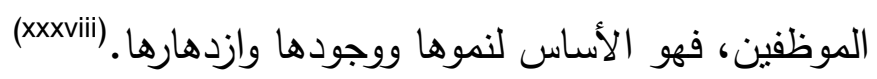

الـروح المعنويـة لـدى الموظـف: إن مواقف المـوظفين واتجاهـاتهم وميـولهم نحـو

مؤسساتهم التي يعملون بها حظيت بقدر كبير من اهتمام الباحثين بل وزاد الاهتمام في مواقف الموظفين بعد أن أتضح أن الروح المعنوية للموظفين تؤثر وبشكل كبير في الأداء الوظيفي. وقد خلصت الكثير من الدراسات إلى أن القيادات الإدارية لها نأثير وبشكل كبير

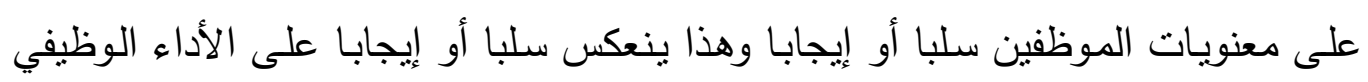
وهي علاقة طردية.

وإذا نجحت المؤسسة في اختيار العاملين، وعملت على خلق روح معنوية قوية لديهم (روح الفريـق فـان ذلك يكفـل الرضـا الوظيفي، وحفظ النظـام وإطاعـة الأوامـر والقوانين

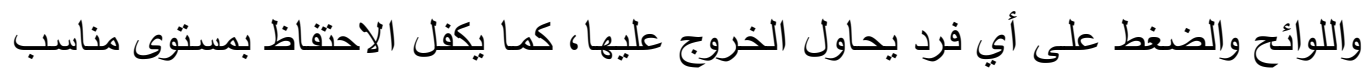

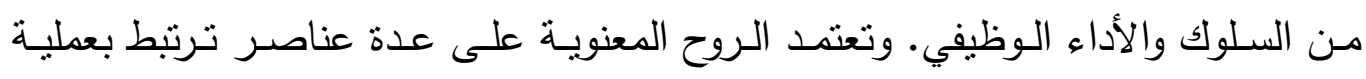

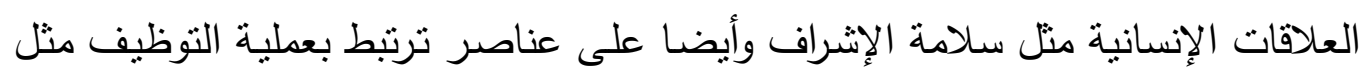
مقابلة الكفايات بالوظائف والتدريب والأجور والترقية والخدمات. (xxxix)

العوامل البيئية: هناك بعض العوامل خارج نطاق سبطرة الفرد والتي يمكن أن تؤئز في

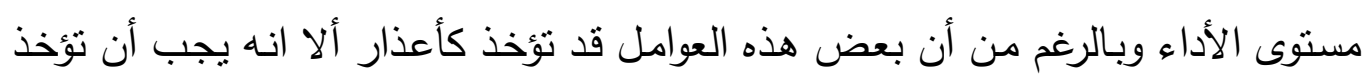
في الاعتبار لأنها في حقيقة الأمر موجودة فعلا والثكل التالي يوضح أهم الهم العوامل البيئية المؤثرة على أداء العاملين، أما العوامل الرئيسية التي تؤثز على أداء الدي الفرد وتعزيزه بحسب درجة توافرها مع كل فرد عامل والتي تمنل في الوقت نفسه مكونات الأداء الفردي هي قدرة

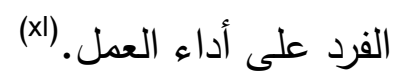




\section{ILA الجمعية المصرية للقر اءة والمعرفة عضو الجمعية الدولية للمعرفة}

الإشراف: لقد أسفرت نتائج الكثبر من الأحداث على أن الكثير من أسباب عدم الرضى

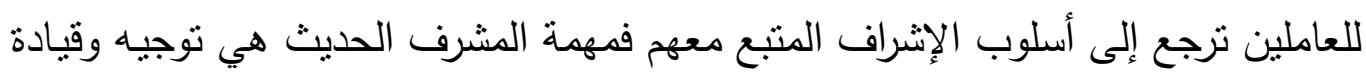
مجموعة من العاملين وتتسيق وجودهم وتقويم أعمالهم للوصول إلى هدف محدد، ويشغل الجانب الإنساني جزءا كبيرا من وظيفة المشرف، ويتضمن ذللك تحفيز العاملين على العمل وبحث مطالبهم، ودراسة مشاكلهم والاستماع إلى مقترحاتهم.

الحوافز : تعبر في أبسط معانيها عن من يحصل عليه الفرد من المؤسسـة مقابل عمله فيها، والتحاق العامل بالمؤسسة وبقائه فيها، وليس في الواقع الا بمقدار ما يعطيه من قيمة في تصوره للحوافز التي يتحصل عليها. ظروف العمل الماديـة: هي الظروف التي تحيط بالفرد أنتاء قيامه بأعمال وظيفته والتي تؤثر بدرجة ملموسة على مقدرته الذهنية والجسمية والتي لا يستطيع التحكم فيها كالحرارة والبرودة والفوضى، والإنارة والتهوية. (xli)

كما أن هناك العديد من العوامل الأخرى التي تؤثر على الأداء والوظيفي وفيما يلي الإشارة إلى عدد منها، كما يلي: التوقعات Expectation: هل يعرف العاملون ما هو متوقع منهج؟ هل تم تحديد أهداف الأداء بشكل واضح وتم تعميمها على الجميع؟ الــدوافع Incentives: هـل هــاك دوافـع محبــة وجذابـة لـدى العـاملين تشـجع وتـدعم الوصول إلى الأداء المرغوب فيه؟ هل هنالك عقبات بالدوافع تعيق الوصسول إلى الأداء

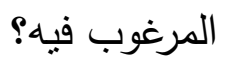

المصـادر Resources: هل يمتلك العاملون الأدوات والمصـادر التي يحتاجونها لتتفيذ الأداء؟ 


\section{الجمعية المصرية للقر اعة والمعرفة عضو الجمعية الدولية للمعرفة}

المهارات والمعارف Skills and knowledge: هل يعرف العاملون كيفية تتفيذ جميع

عناصر عمهم؟

التظذية الراجعة Feed back: هل يتم إيصال نتائج الأداء للعاملين وإبلاغهم عنها؟ هل يتم إبلاغ الإدارة باستمرار بنتائج الأداء.

القدرات Capacity: هل يمنلك العاملون القدرات الفكرية والجسدية والنفسية. تصميم العمل Jop Design: هل هناك أية عقبات أمام الأداء؟ هل هناك تداخل بين

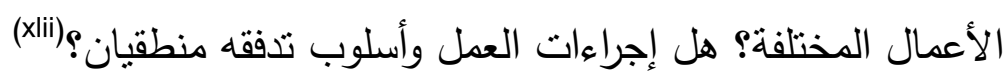
غيـاب الأهـاف المحـدةد: فالمنظمـة التي لا تمنلك خطط تفصـيلية لعملها وأهدافها،

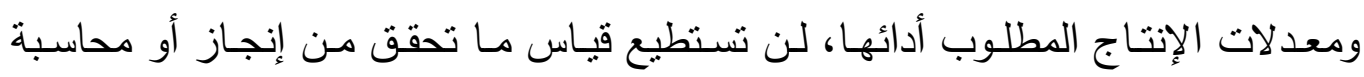

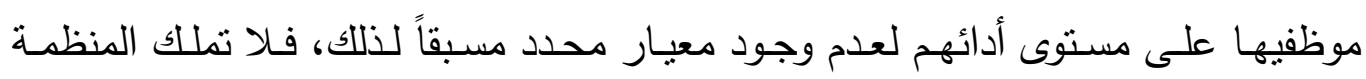

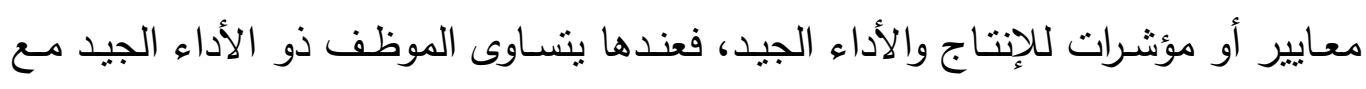
الموظف ذو الداء الضعيف.

عدم المشاركة في الإدارة: إن عدم مشاركة العاملين في المستويات الإدارية المختلفة في

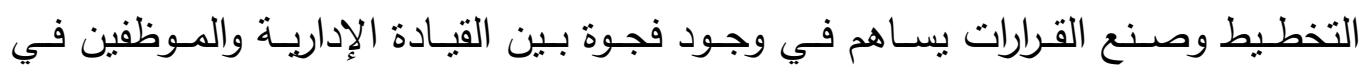

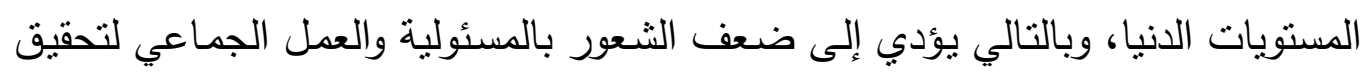

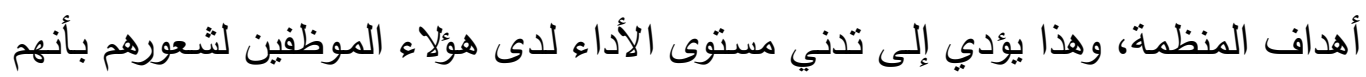

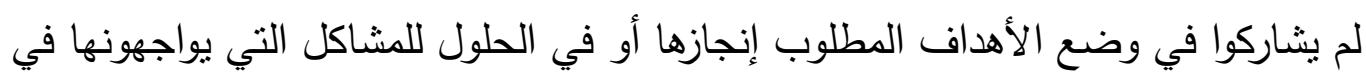
الأداء، وقد يعتبرون أنفسهم مهوشين في الأنظمة. اختلاف مستويات الأداء: من العوامل المؤثرة على أداء الموظفين عدم نجاح الأساليب

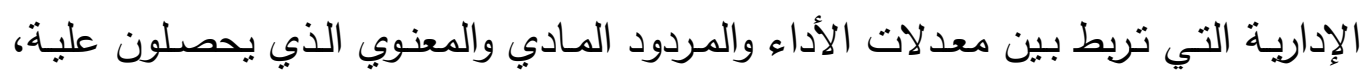

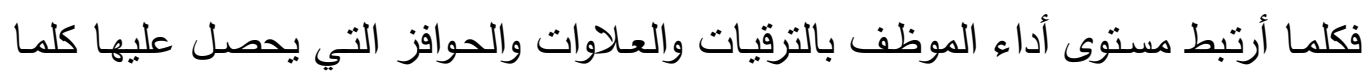

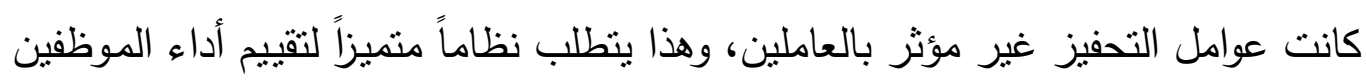




\section{الجمعية المصرية للقر اعة و المعرفة عضو الجمعية الدولية للمعرفة}

ليتم التمبيز الفعلي بين الموظف المجتهد ذو الأداء العالي والموظف المجتهد ذو الأداء المتوسط والموظف الكسول والموظف غير المنتج.

مشـكلات الرضـا الوظيفي: فالرضـا الوظيفي من العوامل الأساسية المؤثز على مستوى الأداء للموظفين، فعدم الرضا الوظيفي أو انخفاضـه يؤدي إلى أداء ضعيف وإنتاجية أقل، والرضا الوظيفي يتأثر بعدد كبير من العوامل التنظيمية والثخصية للموظف، مثل العوامل الاجتماعيـة كالسـن والمؤهـل التعليمسي والجنس والعـادات والتقاليـد، والعوامـل التنظيميـة كالمسئوليات والوجبات ونظام الترقيات والحوافز في المنظمة.

التسيب الإداري: فالتسيب الإداري في المنظمة بعني ضياع ساعات العمل في أمور غير

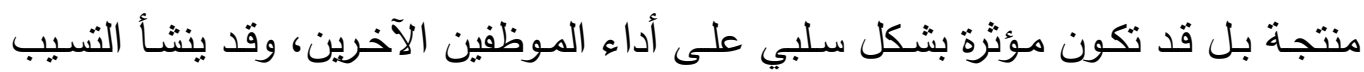

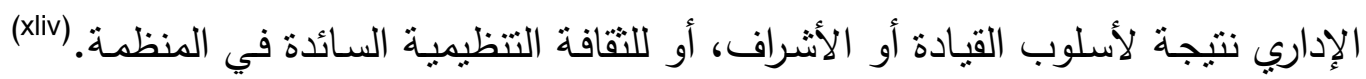

الاختلاف الموجود والملحوظ في حجم العمل قد يؤثثر على الأداء: فالمنظمة التي تعالج حجما كبيرا من العمل قد تحتاج إلى موارد لكل وحدة أقل مما تحتاج إليه أخرى لديها حجم

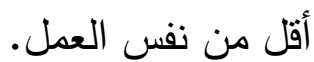
وجود أو عدم وجود الأعمال المتأخرة قد يؤثر في معدل الإنتاج: إذ أن القدر الضئيل من

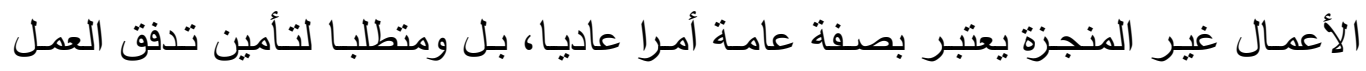

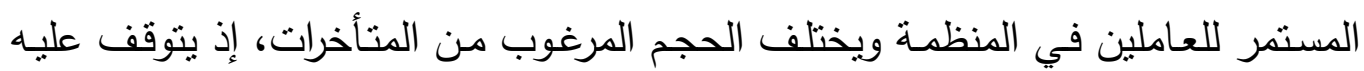
ثبات انسياب العمل وكمية ودرجـة التقلبات فيهه، وبسبب النقص في العمل المتاح وقت الانتظار لدى العاملين انخفاضا في معدل الإنتاج على النقيض، فإن كثرة العمل المتأخر

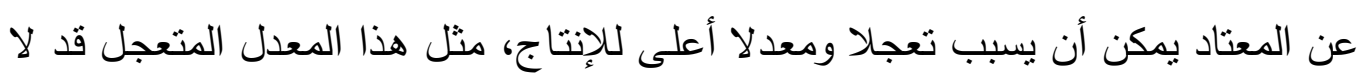
يمكن تحقيقه دائما ويتولا عنه انخفاض في نوعية المنتج النهائي. 


\section{الجمعية المصرية للقر اعة والمعرفة عضو الجمعية الدولية للمعرفة المي}

التحسينات الإجرائية والتنظيمية ذات أثر مباشُر على الأداء: يتوقف معدل الإتتاج على عدة عوامل

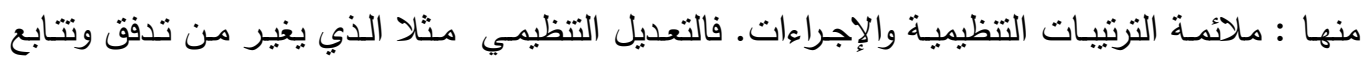

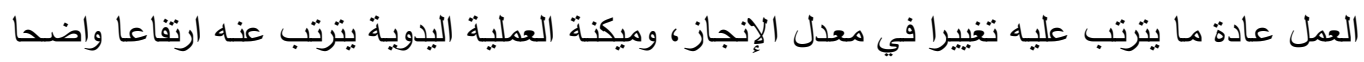
في معدل الإنتاج وبالمثل، فإن اختصار خطوات العمل في عملية ما يقلل من الموارد المطلوبة لإنهاء وحدة العمل. في مدل الإناج

الأداء في العمليات المتماثلة قد يتباين بحب الموقع الجغرافي للوحدات من جراء الظروف المحلية، فقد تتباين معدلات الإنتاج بسبب الظروف المحلية حتى ولو أدى نفس النشاط في مواطن مختلفة بنفس درجة لإنة

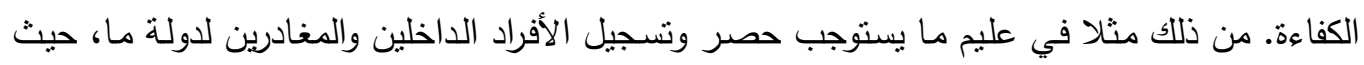

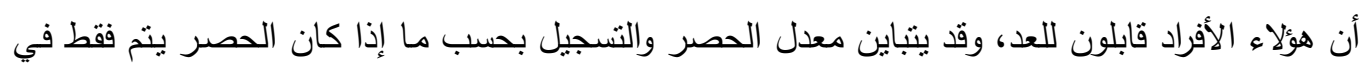

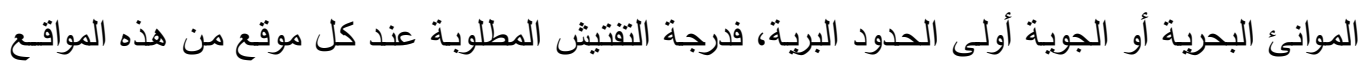

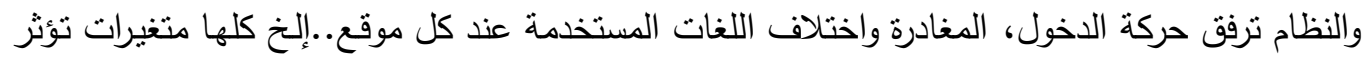
على معدل الإنتاج.

ه-نوعية وحدة العمل التام قد تقضي إلى معدلات مختلفة للإنتاج فمعدلات الأداء كمية بطبيعتها وقد

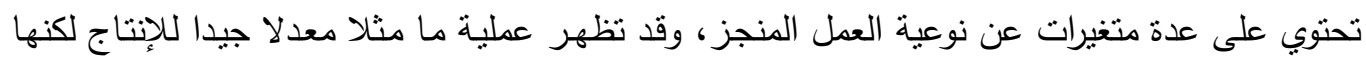
من الناحية النوعية قد تكون ذات أداء رديء.

كما يرى بعض الباحثين أن هناك أربعة عوامل تؤيثر في الأداء يمكن إيجازها فيما يلي:

- - - دقة المعلومات التي على أساسها تتخذ العديد من قرارات النقل والترقية. - - سلوك المرؤوسين بإعادة النظر في تصرفاتهم لكونهم يعدون الحجر الأساسي للمنظمـة والجزء الفاعل فئل

$$
\text { في تقييم الأداء. }
$$

- - تفعيل العملية التتظيمية التي من خلالها يمكن مراجعة خطط ونظم العمل. - - تحسين وتطوير مستويات الأداء بالمنظمة التي على أساسها اعتمادا على نتائجها بقيم الأداء الكلي لالمنظمة. (xlvi) 
الجمعية المصرية للقر اءة والمعرفة عضو الجمعية الدولية للمعرفة

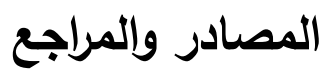

(i) DONALD, R. BROWN, and DON HARVEY. An Experiential approach to organization development. UPPER SADDLE, 2004.

(ii)

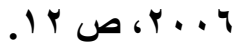

(iii) . IVV

والتوزيع، واويـة محمـد، إدارة المـوارد البثـرية: رؤيـة مسـتقبلية، القـاهرة: الدار الجامعيـة للطبع والنشـر

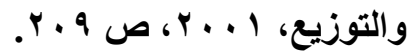

الإديد، البارئ إبراهيم درة، تكنولوجيا الأداء البشري في المنظمات، منشورات المنظمة العربيـة للتنمية

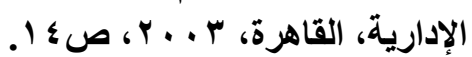

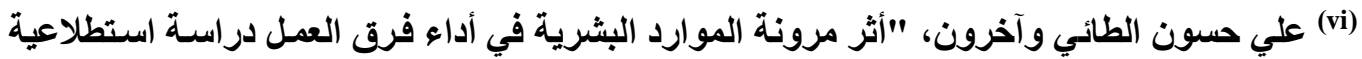

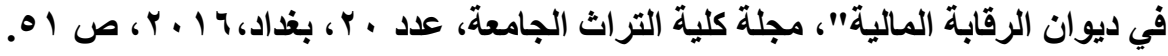

(أحمد صقر عاشور، إدارة القوى العاملة: الأسس السلوكية وأدوات البحث التطبيقي، دار النهضـة

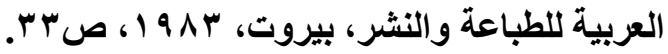

(viii)

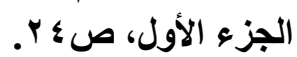

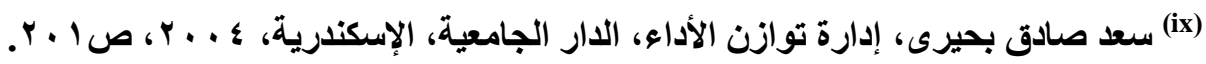

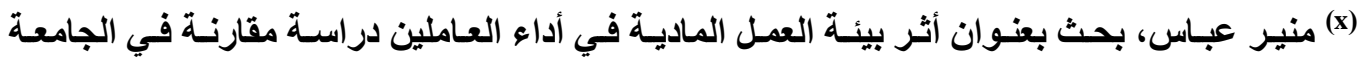

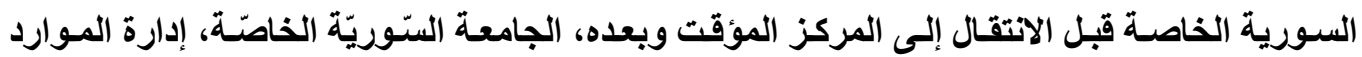

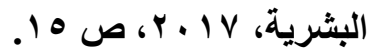

(xi)

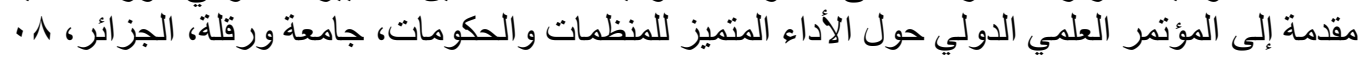

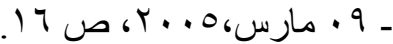
(xii)

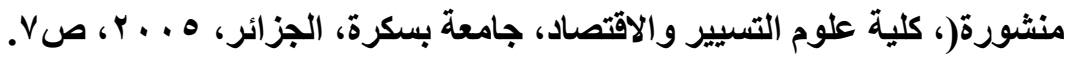


الجمعية المصرية للقر اعة والمعرفة عضو الجمعية الدولية للمعرفة

http://badr-cu34.yoo7.com/t88-topic المؤسسة الاقتصادية، من موقع: (xiii) زهزائل عبدان الحفاظ العواملة، إدارة المنشآت العامة،" الأسس النظرية وتطبيقاتها في الأردن"، دار

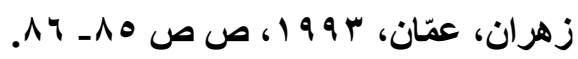

عايد عبد الله العصيمى، المسؤولية الاجتماعية للثركات نحو التنمية المستدامة، مكتبة الياروزي، (xv)

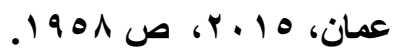

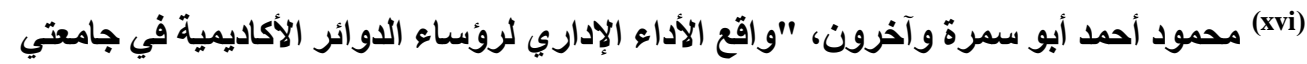

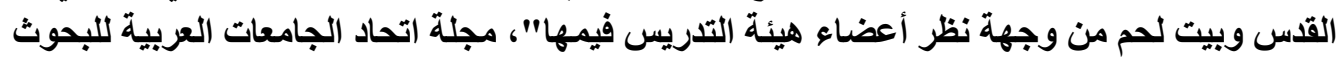

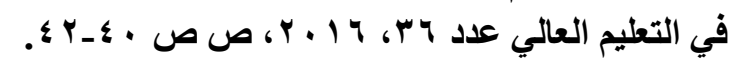

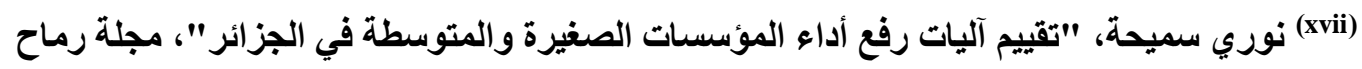

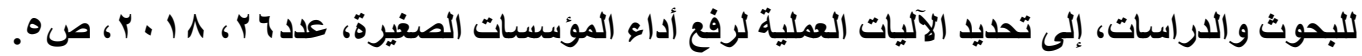

$$
\text { (xviii) }
$$

عامر حجل، أثر ضـغوط العمل على أداء المراجع الخـارجي، رسـالة ماجستير غير منشسورة، كلية (xx)

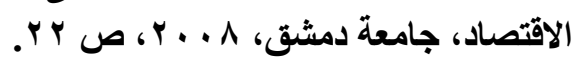

https://hrdiscussion.com/hr116090.html عناصر الأداء الوظيفي، من موقع: (xxi)

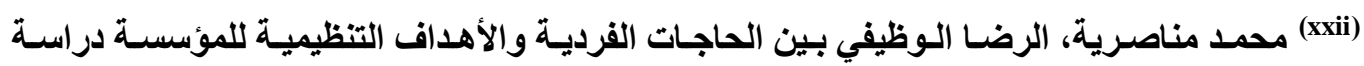

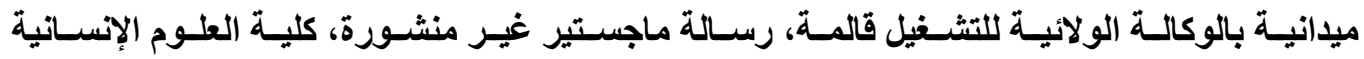

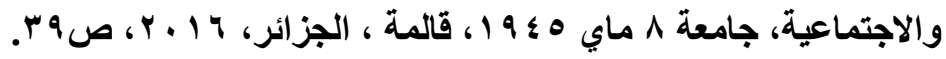

وإبرا هيم محمد المحاسنة، إدارة تقيبم الأداء الوظيفي بين النظريـة والتطبيق، دار جريـر للنشر

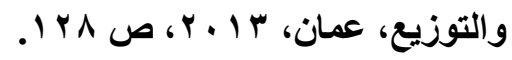

(xxiv)

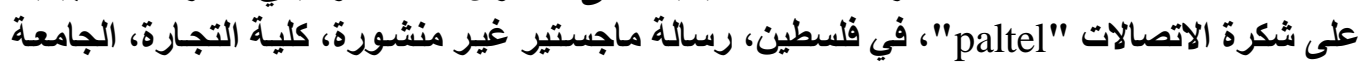

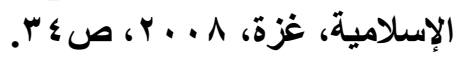

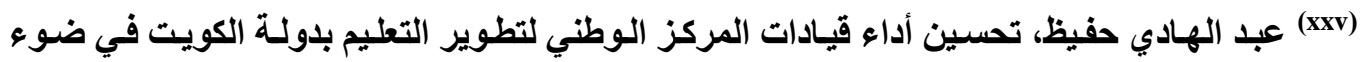

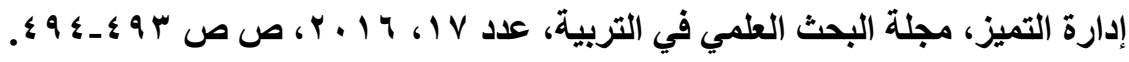


الجمعية المصرية للقر اعة والمعرفة عضو الجمعية الدولية للمعرفة

(xxvi)

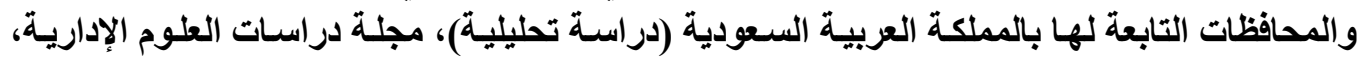

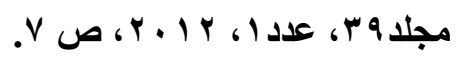
عصمت سليم القرالة، مرجع سابق، ص 1 (xxvii)

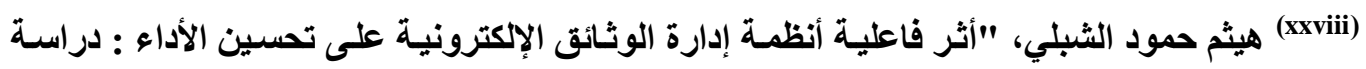

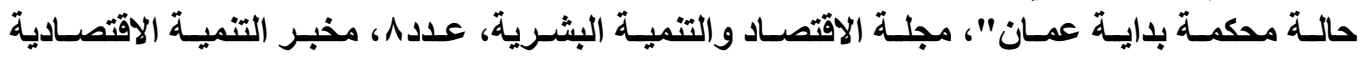

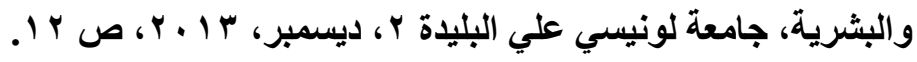
(xxix)

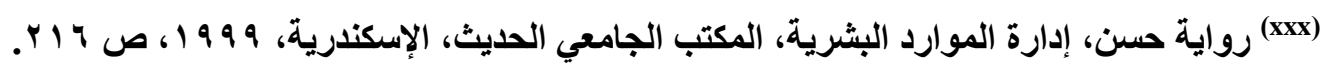

$$
\text { محمد سعيد أنور سلطان، مرجع سابق، ص • r rxxi) }
$$

(xxxii)

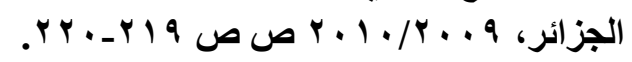

(xxxiii)

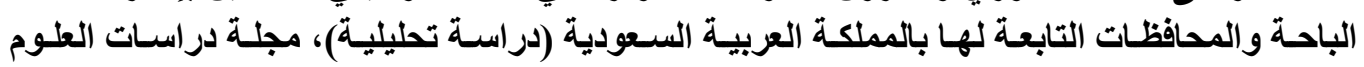

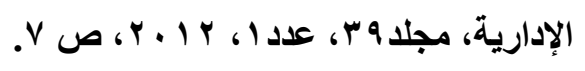

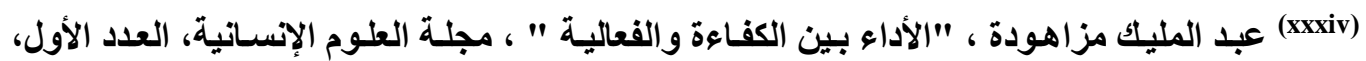

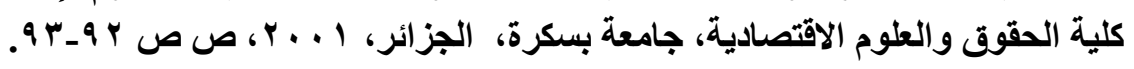
جامعة (xxv)

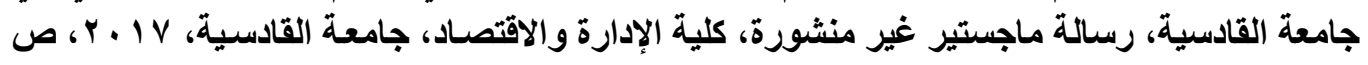

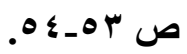

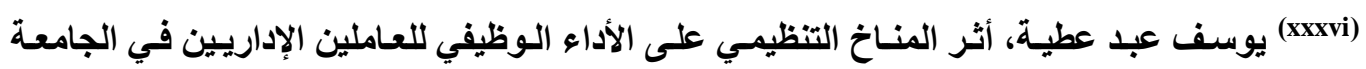

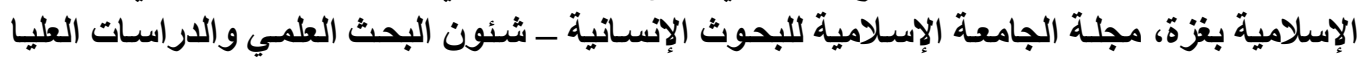

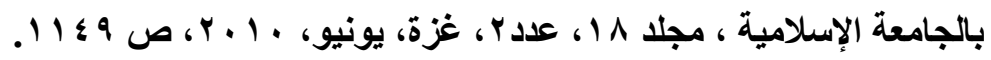
(المرجع السابق، ص \& (xxxvii) 


\section{ILA الجمعية المصرية للقر اءة والمعرفة عضو الجمعية الدولية للمعرفة}

(xxxviii)

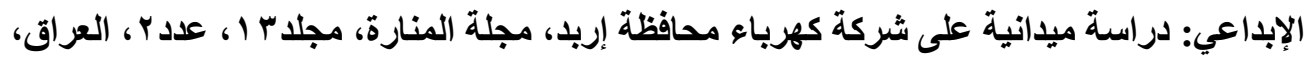

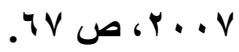

(xxxix)

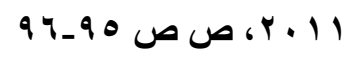

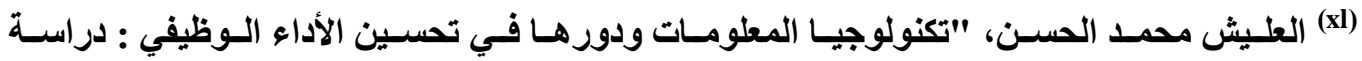

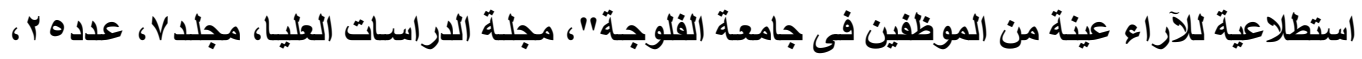

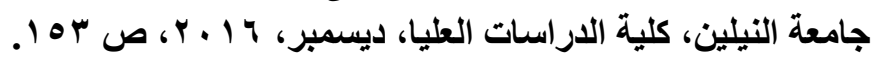

(xli)

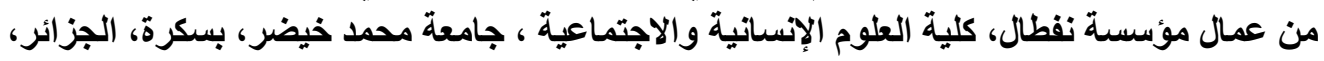

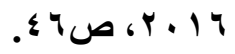
(xlii) (xliii) (xliv) منال أحمد البارودي، القائد المتميز وأسرار الإبداع القيادي، المجموعة العربية للتدريب والنشر،

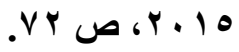
https://hrdiscussion.com/hr49451.html العو امل المؤثرة في الأداء، من موقع: (xlv)

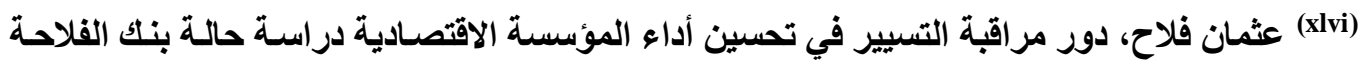

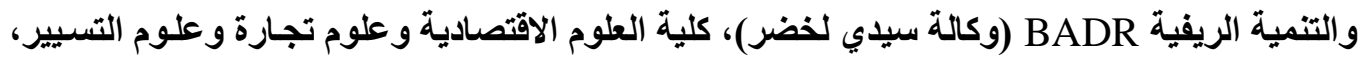

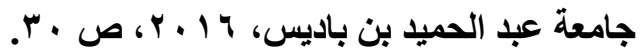

